10

\title{
Люминесцентные свойства нестехиометрических кристаллов ниобата лития различного состава и генезиса (обзор)
}

\section{(C) М.В. Смирнов, Н.В. Сидоров, М.Н. Палатников}

Институт химии и технологии редких элементов и минерального сырья им. И.В. Тананаева Федерального исследовательского центра „Кольский научный центр Российской академии наук“, 184209 Апатиты, Россия

e-mail: m.smirnov@ksc.ru

Поступила в редакцию 09.06.2021 г.

В окончательной редакции 20.09.2021 г.

Принята к публикации 24.09.2021 г.

Дан краткий обзор особенностей дефектной структуры и исследований люминесцентных свойств нелинейно-оптических кристаллов ниобата лития различного состава и генезиса. Установлено, что электронно-дырочная пара $\mathrm{Nb}_{\mathrm{Nb}^{4+}}-\mathrm{O}^{-}$в кислородно-октаэдрическом кластере $\mathrm{NbO}_{6}$ люминесцирует в коротковолновой области видимого спектра $(400-500 \mathrm{~nm})$, в то время как точечные дефекты с участием $V_{\mathrm{Li}}$ и биполяронные пары $\mathrm{Nb}_{\mathrm{Nb}^{4+}}-\mathrm{Nb}_{\mathrm{Li}^{4+}}$ - в длинноволновой области $(500-620 \mathrm{~nm})$. При соотношении $[\mathrm{Li}] /[\mathrm{Nb}] \approx 1$ благодаря уменьшению собственных центров свечения происходит тушение люминесценции в видимой области спектра. Показано, что наличие поляронной люминесценции в ближней ИК области $(700-1050 \mathrm{~nm})$ обусловлено поляронами малого радиуса $\mathrm{Nb}_{\mathrm{Li}^{4+}}$ и примесных ионов $\mathrm{Cr}^{3+}$, локализующихся в литиевых и ниобиевых октаэдрах. Обнаружен перенос энергии между центрами свечения в видимой и ближней ИК областях спектра. При этом излучательная рекомбинация преобладает в ближней ИК области. Легирование кристаллов цинком и магнием $\mathrm{LiNbO}_{3}$ при концентрациях $[\mathrm{ZnO}]<4.46 \mathrm{~mol} \%$ и $[\mathrm{MgO}]<5.29 \mathrm{~mol} \%$ приводит к подавлению излучательной рекомбинации собственных дефектов $\left(\mathrm{V}_{\mathrm{Li}}\right.$, $\left.\mathrm{Nb}_{\mathrm{Nb}^{4+}}-\mathrm{Nb}_{\mathrm{Li}^{4+}}\right)$. Однако при более высоких концентрациях наблюдается увеличение вклада коротковолновой составляющей спектра за счет вытеснения легирующими примесями $\mathrm{Zn}$ и $\mathrm{Mg}$ ионов $\mathrm{Nb}$, находящихся в основных позициях.

Ключевые слова: монокристалл ниобат лития, точечные дефекты, люминесценция, центры свечения.

DOI: $10.21883 /$ OS.2022.01.51905.14-21

\section{Введение}

Монокристалл ниобата лития $\left(\mathrm{LiNbO}_{3}\right)$ является важным функциональным оптическим материалом, широко применяемым в телекоммуникационном оборудовании, в интегральной оптике и лазерной технике. Ниобат лития представляет собой глубоко дефектную кислороднооктаэдрическую фазу переменного состава с широкой областью гомогенности на фазовой диаграмме, что позволяет изменять стехиометрию кристалла (отношение $[\mathrm{Li}] /[\mathrm{Nb}])$, а также вводить в структуру легирующие добавки, изменяя тем самым состояние дефектности и физические характеристики кристалла $[1,2]$. Номинально чистые кристаллы $\mathrm{LiNbO}_{3}$ конгруэнтного $([\mathrm{Li}] /[\mathrm{Nb}]=0.946)$ и стехиометрического составов $([\mathrm{Li}] /[\mathrm{Nb}]=1)$ отличаются существенно разными по величине напряженностью коэрцитивного поля порядка $\sim 21$ и $\sim 5 \mathrm{kV} / \mathrm{mm}$ соответственно. Но стехиометрические кристаллы, выращенные из расплава с $58.6 \mathrm{~mol} \%$ $\mathrm{Li}_{2} \mathrm{O}$, характеризуются намного более сильным эффектом фоторефракции [3-6]. Легирование кристаллов магнием или цинком позволяет снизить эффект фоторефракции и уменьшить величину коэрцитивного поля (до 4.6 и $1.4 \mathrm{kV} / \mathrm{mm}$ для $\mathrm{Mg}$ и $\mathrm{Zn}$ соответственно [7,8]), что важно для создания материалов для преобразования лазерного излучения на периодически поляризованных доменах микронных и субмикронные размеров [9-14]. При этом лимитирующим фактором является наличие люминесценции.

Идеальный стехиометрический кристалл имеет окно прозрачности в области 320-5000 nm [15]. В идеальном стехиометрическом кристалле не должно быть центров люминесценции. Однако в реальных кристаллах $\mathrm{LiNbO}_{3}$ всегда присутствуют точечные дефекты $\mathrm{Nb}_{\mathrm{Li}}$ - катионы ниобия, расположенные в позициях катионов лития идеальной структуры. Особенно велика концентрация таких дефектов в кристаллах, выращенных из расплава с избытком ниобия $([\mathrm{Li}] /[\mathrm{Nb}]<1)$. Так, в конгруэнтном кристалле концентрация точечных дефектов $\mathrm{Nb}_{\mathrm{Li}}$ coставляет $\approx 6$ at\% [16] или $1 \mathrm{~mol} \%$ [17]. Наличие дефектов $\mathrm{Nb}_{\mathrm{Li}}$ вследствие сохранения зарядовой электронейтральности кристалла, в свою очередь, приводит к образованию в кристалле целого спектра точечных и комплексных дефектов, которые выступают в качестве дырочных и электронных ловушек захвата. Роль дефектов в виде мелких и глубоких электронных ловушек в запрещенной зоне, а также дефектов, изменяющих поляризуемость кислородно- октаэдрических кластеров 
$\mathrm{MeO}_{6}\left(\mathrm{Me}-\mathrm{Li}^{+}, \mathrm{Nb}^{5+}\right.$, легирующий катион $)$ и упорядочение структурных единиц катионной подрешетки вдоль полярной оси является определяющей в формировании практически значимых физических свойств, в частности, люминесценции, фоторефракции, спонтанной поляризации и коэрцитивного поля. Поэтому для создания материалов на основе кристалла $\mathrm{LiNbO}_{3}$ для генерации и преобразования лазерного излучения помимо уменьшения фоторефрактивных свойств необходимо уменьшить в кристалле количество дефектов, отвечающих за спонтанную излучательную рекомбинацию в оптической области спектра.

В настоящей работе выполнен краткий обзор исследований дефектной структуры кристаллов ниобата лития разного состава и генезиса с целью установления влияния дефектов различного вида на люминесцентные характеристики номинально чистых кристаллов $\mathrm{LiNbO}_{3}$, a также кристаллов, легированных магнием и цинком. В обзоре затрагиваются только проблемы излучательной рекомбинации центров свечения матрицы кристалла $\mathrm{LiNbO}_{3}$, но не рассматриваются внутриконфигурационные $4 f^{n}-4 f^{n}$-переходы редкоземельных элементов (P3Э) и сопутствующие механизмы люминесценции (upконверсия, перенос энергии „матрица-РЗЭ“ или „РЗЭР3Э“, нелинейное оптическое усиление), которые подробно освящены в работах [18-21]. Акцент сделан на исследованиях и анализе литературных данных по собственному свечению матрицы кристалла ниобата лития в зависимости от стехиометрии, типа легирующей примеси и ее концентрации, условий отжига и т.д. и сравнении их с нашими экспериментальными данными по фотолюминесценции кристаллов $\mathrm{LiNbO}_{3}$ различного состава и генезиса. Статья имеет материаловедческий характер. Цель работы - не интерпретация спектров люминесценции (это уже сделано в литературе $[19,20,22])$, а исследование люминесценции кристаллической матрицы с целью получения оптических материалов для преобразования оптического излучения с максимально низкой фотолюминесценцией. Работа состоит из трех разделов. В первом разделе описаны методы приготовления образцов и техника измерений. Во втором представлена информация об основных точечных дефектах, образующихся в кристалле $\mathrm{LiNbO}_{3}$ при изменении стехиометрии и легировании различными концентрациями катионов $\mathrm{Mg}^{2+}$ и $\mathrm{Zn}^{2+}$. В третьем разделе представлена информация о люминесцентных свойствах исследованных кристаллов $\mathrm{LiNbO}_{3}$ и дана характеризация основных центров свечения матрицы.

\section{1. Материалы и методы}

Все кристаллы были выращены в воздушной атмосфере методом Чохральского из гранулированной шихты метаниобата лития, синтезированной на основе методики ИХТРЭМС КНЦ РАН [23]. Конгруэнтные кристаллы $\left(\mathrm{LiNbO}_{3 \text { cong }}\right)$ выращивались из конгруэнтного расплава $([\mathrm{Li}] /[\mathrm{Nb}]=0.946)$. Кристаллы $\mathrm{LiNbO}_{3}$ стехиометрического состава были получены двумя способами: из расплава с $58.6 \mathrm{~mol}_{0} \mathrm{Li}_{2} \mathrm{O}\left(\mathrm{LiNbO}_{3 \mathrm{st}}\right)$ и методом HTTSSG (High temperature top seeded solution growth) из расплава конгруэнтного состава с добавлением щелочного флюса $\mathrm{K}_{2} \mathrm{O} \approx 6.0 \mathrm{~mol} \%\left(\mathrm{LiNbO}_{3 \mathrm{st}}: \mathrm{K}_{2} \mathrm{O}\right)$. Кристаллы $\mathrm{LiNbO}_{3}$, легированные $\mathrm{Zn} \mathrm{c} \mathrm{концентрацией} \mathrm{0.07,} \mathrm{1.19,}$ $2.01,4.46,5.50$ и $6.50 \mathrm{~mol} \% \mathrm{ZnO}$ и легированные $\mathrm{Mg}$ с концентрацией $0.19,1.65,2.13,3.02,5.29,5.91 \mathrm{~mol} \%$, были получены с использованием метода прямого легирования расплава. Более подробная информация по выращиванию кристаллов $\mathrm{LiNbO}_{3}$ различного состава и генезиса представлена в работах [2,24]. Концентрация следовых количеств неконтролируемых примесей в кристаллах не превышает $1 \cdot 10^{-3}$ для $\mathrm{Mo}, \mathrm{Fe}, \mathrm{Ti}, \mathrm{Si}, \mathrm{Pb}, \mathrm{Ni}$, $\mathrm{Cr}, \mathrm{Co} \mathrm{и} 5 \cdot 10^{-4}$ wt\% для $\mathrm{Al}, \mathrm{Cu}, \mathrm{Mn}, \mathrm{V}, \mathrm{Mg}, \mathrm{Sn}$.

Монодоменизация кристаллов осуществлялась методом высокотемпературного электродиффузионного отжига при охлаждении образцов со скоростью $20^{\circ} / \mathrm{h}$ в температурном интервале от $\sim 1240-890^{\circ} \mathrm{C}$ в условиях приложения электрического напряжения [23]. Контроль степени монодоменности осуществлялся методом импедансной спектроскопии и измерения величины статического пьезомодуля $\left(d_{333 \mathrm{c \tau}}\right)$ кристаллической були. Исследуемые образцы, вырезанные из кристаллической були, представляли собой прямоугольные параллелепипеды с размерами $\sim 8 \times 7 \times 6 \mathrm{~mm}^{3}$, ребра которых совпадали с направлениями кристаллографических осей $X, Y, Z(Z-$ полярная ось кристалла).

Измерение спектров фотолюминесценции проводилось с поверхностных макродефектов и объема исследуемых кристаллов $\mathrm{LiNbO}_{3}$ с помощью спектрографа SOL SL-100M с ПЗС-детектором FLI ML 1107 BlackIlluminated (Hamamatsu) в двух диапазонах длин волн: $380-800$ и 600-1050 nm, в нормальных условиях. ПЗС-матрица в рабочем режиме охлаждалась элементом Пельтье до $-30^{\circ} \mathrm{C}$. Ширина входной щели монохроматора составляла $0.25 \mathrm{~mm}$ для измерений с поверхности кристалла $\mathrm{LiNbO}_{3}$ и $1.00 \mathrm{~mm}$ для измерений с объема исследуемых кристаллов. В качестве источника возбуждения люминесценции использовался непрерывный $\mathrm{He}-\mathrm{Cd}$-лазер $\left(\lambda_{\mathrm{ex}}=325 \mathrm{~nm}, 15 \mathrm{~mW}\right)$. Каждый спектр фотолюминесценции нормировался на фоновый сигнал.

\section{2. Дефектная структура кристалла $\mathrm{LiNbO}_{3}$}

Структура кристалла $\mathrm{LiNbO}_{3}$ любого состава в пределах области гомогенности описывается пространственной группой симметрии $R 3 c$ с двумя формульными единицами в элементарной ячейке. Кристалл состоит из чередующихся кислородных октаэдров $\mathrm{O}_{6}$, каждый из которых повернут друг относительно друга на $120^{\circ}$. Две трети октаэдров $\mathrm{O}_{6}$ содержат ионы $\mathrm{Nb}$ и Li, а треть октаэдров остаются вакантными, так что вдоль полярной оси кристалла образуется цепочка 
$\ldots-\mathrm{Nb}-\mathrm{Li}-\square-\mathrm{Nb}-\mathrm{Li}-\square-\mathrm{Nb}-\mathrm{Li}-\square-\ldots \quad(\square-$ пустой октаэдр) (рис. 1). В нормальных условиях кристалл ниобата лития находится в сегнетоэлектрической фазе благодаря смещению ионов $\mathrm{Li}$ и $\mathrm{Nb}$ из центросимметричного положения относительно кислородной плоскости вдоль направлении полярной оси $c$ на 0.44 и $0.26 \AA$ соответственно $[1,25]$.

В номинально чистых нестехиометрических кристаллах и в легированных кристаллах $\mathrm{LiNbO}_{3}$ распределение основных $(\mathrm{Li}$ и $\mathrm{Nb})$ и примесных катионов по октаэдрам вдоль полярной оси чрезвычайно сложное и трудно поддается математическому моделированию. Обычно это делается методом полнопрофильного рентгеноструктурного анализа (метод Ритвельда) с использованием вакансионных сплит-моделей [26]. Первоначально авторами работы [27] была предложена вакансионная модель, учитывающая одновременное образование вакансий по кислороду и литию, $\left[\mathrm{Li}_{1-2 x} \mathrm{~V}_{2 x}\right][\mathrm{Nb}]\left[\mathrm{O}_{3-x} \mathrm{~V}\right]$, и по мере увеличения стехиометрии (отношения $[\mathrm{Li}] /[\mathrm{Nb}]$ ) доля таких дефектов уменьшается. Данная модель не согласуется с данными работ [28,29], в которых увеличение плотности кристалла происходит при уменьшении соотношения $[\mathrm{Li}] /[\mathrm{Nb}]$. При этом избыточные атомы ниобия преимущественно внедряются в позиции лития $\left(\mathrm{Nb}_{\mathrm{Li}}\right)$, так как размеры литиевого октаэдра больше, чем ниобиевого. Для сохранения электронейтральности кристалла эффективный избыточный заряд ниобия, $4|e|$, где $e-$ заряд электрона, компенсируется четырьмя вакансиями по литию, $\mathrm{V}_{\mathrm{Li}}$ (модель литиевых вакансий, $\left.\left[\mathrm{Li}_{1-5 x} \mathrm{Nb}_{x} \mathrm{~V}_{4 x}\right][\mathrm{Nb}]\left[\mathrm{O}_{3}\right]\right)$ [28]. Модель литиевых вакансий хорошо согласуется с данными рентгеноструктурного анализа [30]. Кроме того, образование вакансий по кислороду энергетически невыгодно [31].

Увеличение плотности кристалла с уменьшением стехиометрии можно объяснить и с точки зрения образования ниобиевых вакансий $\left(V_{\mathrm{Nb}}\right)$. Так, при тщательном исследовании ЯМР ${ }^{96} \mathrm{Nb}$ [32] кристалла $\mathrm{LiNbO}_{3}$ была предложена другая вакансионная модель: модель ниобиевых вакансий, $\left[\mathrm{Li}_{1-5 x} \mathrm{Nb}_{5 x}\right]\left[\mathrm{Nb}_{1-4 x} \mathrm{~V}_{4 x}\right]\left[\mathrm{O}_{3}\right]$, в которой ниобий находится в позиции лития и вблизи него образуется вакансия по ниобию, $\mathrm{V}_{\mathrm{Nb}}$. Модель развивали авторы работы [16] на основе рентгеноструктурных исследований кристалла $\mathrm{LiNbO}_{3}$.

Сравнение моделей литиевых и ниобиевых вакансий представлено в работах [30,31,33,34]. Модель литиевых вакансий описывает дефектную структуру лучше по данным нейтронографии и рентгенографии в отличие от модели ниобиевых вакансий [30] для кристаллов $\mathrm{LiNbO}_{3}$ с соотношением $[\mathrm{Li}] /[\mathrm{Nb}]=0.992,0.942,0.887$. С увеличением концентрации ионов $\mathrm{Nb}$ в кристаллической структуре ниобата лития ионы $\mathrm{Nb}^{5+}$ в основном октаэдре стремятся к центросимметричному положению, а ионы $\mathrm{Li}^{+}$при этом, наоборот, стремятся сместиться вдоль полярной оси $z$ из центра октаэдра к ближайшей кислородной плоскости [30]. На основе расчетов частоты мягкой моды и температуры Кюри дефектная структура кристалла $\mathrm{LiNbO}_{3}$ лучше описывается в рамках модели литиевых вакансий [33]. Кроме того, компьютерное моделирование показало, что модель литиевых вакансий более энергетически выгодна по сравнению с моделью ниобиевых вакансий [31,34]. Однако на основе анализа частотной зависимости $\mathrm{E}\left(\mathrm{TO}_{1}\right)-$ и $\mathrm{A}_{1}\left(\mathrm{TO}_{1-4}\right)$-фононов кристаллической решетки от состава кристалла установлено, что дефектную структуру кристалла $\mathrm{LiNbO}_{3}$ разного состава можно описывать в рамках сплитмодели, объединяющей модели ниобиевых и литиевых вакансий, причем последняя доминирует с конгруэнтным составом $[\mathrm{Li}] /[\mathrm{Nb}] \geq 0.946[35]$.

B работе [36] распределение основных катионов $(\mathrm{Nb}, \mathrm{Li})$ и вакансий $(\square)$ вдоль полярной оси кристалла $\mathrm{LiNbO}_{3}$ исследовалось в рамках структуры псевдоильменита (рис. 1). Компьютерное моделирование кластеров в структуре кристалла ниобата лития [31] показывает, что возможны и стабильны две модификации структуры псевдоильменита. При этом энергия кристаллической решетки, приходящаяся на элементарную ячейку в структуре обеих модификаций, отличается лишь на $0.3 \%$. Периоды элементарной ячейки при этом увеличиваются в среднем на $2 \%$ по сравнению со структурой псевдоильменита [37]. В этой связи авторы предполагают, что возможно одновременное сосуществование кластеров обеих модификаций в структуре кристалла $\mathrm{LiNbO}_{3}$, что позволяет расширить уже имеющиеся дефектные модели. Факт одновременного сосуществования кластеров двух модификаций может подтверждать наличие „лишних“ малоинтенсивных линий (не соответствующих фундаментальным колебаниям решетки) в спектре комбинационного рассеяния света (КРС) [25]. При этом количество „лишних“ линий приблизительно равно количеству линий, соответствующих фундаментальным колебаниям решетки. В работе [36] предложено, что наличие дефектов $\mathrm{V}_{\mathrm{Nb}}$ в структуре псевдоильменита кристалла $\mathrm{LiNbO}_{3}$ можно, как и в структуре ильменита, интерпретировать на основе модели литиевых вакансий. Авторы работы [37] утверждают, что в спектре КРС слабый максимум при $738 \mathrm{~cm}^{-1}$ соответствует фонону в структуре ильменитовой упаковки кристалла $\mathrm{LiNbO}_{3}$. В спектре КРС кристалла $\mathrm{LiNbO}_{3 \text { cong }}$ (в отличие от спектра $\left.\mathrm{LiNbO}_{3 \mathrm{st}}\right)$ в $180^{\circ}$ геометрии рассеяния в поляризациях $((Y X),(X Y),(Y Y),(X X))$ данный максимум уверенно проявляется при возбуждении спектров как в видимой, так и ближней ИК области [38].

Для легированных кристаллов модель дефектной структуры и механизм вхождения легирующей примеси в решетку кристалла будет зависеть от вида и концентрации легирующей примеси. При этом вхождение легирующих элементов имеет явно выраженный пороговый характер. В определенных концентрационных диапазонах физические характеристики (температура Кюри, периоды кристаллической решетки, проводимость и т.д.) меняются скачкообразно $[2,25]$. Воздействие легирующих „нефоторефрактивных“ катионов $\mathrm{Zn}^{2+}, \mathrm{Mg}^{2+}$ 


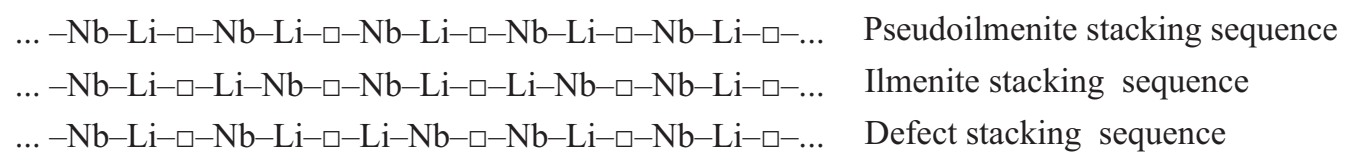

Рис. 1. Расположение катионов вдоль полярной оси $c$ в псевдоильменитовой и ильменитовой структурах и предполагаемая сплит-структура кристалла $\mathrm{LiNbO}_{3}[25,31]$.

идр. на оптические свойства и композиционную однородность кристалла $\mathrm{LiNbO}_{3}$ сводится в основном к изменению порядка чередования вдоль полярной оси основных катионов $\left(\mathrm{Li}^{+}\right.$и $\left.\mathrm{Nb}^{5+}\right)$, концентрации следовых количеств примесных катионов и собственных точеных и комплексных дефектов. При этом существенным технологическим преимуществом кристаллов $\mathrm{LiNbO}_{3}: \mathrm{Zn}$ является то, что при изменении концентрации Zn в кристалле происходит более плавное изменение состояния дефектности и его физических характеристик, чем при изменении концентрации $\mathrm{Mg}$ [2]. Описание дефектной структуры в легированных кристаллах $\mathrm{LiNbO}_{3}: \mathrm{Zn}$ и $\mathrm{LiNbO}_{3}: \mathrm{Mg}$ в данной работе будет строиться на основе модели литиевых вакансий, так как она играет доминирующую роль по сравнению с моделью ниобиевых вакансий.

Из-за большего размера литиевого октаэдра относительно ниобиевого расстояния между ионами $\mathrm{Li}^{+}$и ближайшими ионами $\mathrm{O}^{-}$составляют 2.072 и $2.273 \AA$, тогда как для иона $\mathrm{Nb}^{5+}-1.885$ и $2.102 \AA$ [39]. Соответственно механизм вхождения при малой концентрации легирующей примеси цинка и магния в решетку кристалла $\mathrm{LiNbO}_{3}$ преимущественно начинается с внедрения в литиевые позиции. При легировании малыми концентрациями $\mathrm{Mg}$ и $\mathrm{Zn}$ механизм вхождения определяется внедрением в позиции лития с одновременным уменьшением количества дефектов $\mathrm{Nb}_{\mathrm{Li}}$ [40]. Полное вытеснение ионов $\mathrm{Nb}$ ионами $\mathrm{Mg}$ наблюдается при концентрации $3 \mathrm{~mol} \%$ [37]. При более высоких концентрациях $\mathrm{Mg}$ входит в структуру как в литиевые, так и ниобиевые позиции [40]. Если учитывать дефекты упаковки, то увеличение концентрации $\mathrm{Mg}$ должно сопровождаться уменьшением в спектре КРС интенсивности линии с частотой $738 \mathrm{~cm}^{-1}$. Полное исчезновение этой линии из спектра наблюдается в области между 2.0 до $4.0 \mathrm{~mol} \% \mathrm{MgO}$. Авторы [37] на основе данных по КРС спектроскопии заключают, что это соответствует полному отсутствию кластеров со структурой ильменита в структуре кристалла ниобата лития. Аналогичные закономерности наблюдаются при легировании атомами $\mathrm{In}^{3+}$ и $\mathrm{Ti}^{4+}$ [37]. Благодаря более плавному вхождению $\mathrm{Zn}$ в кристаллическую решетку $\mathrm{LiNbO}_{3}$ с увеличением концентрации будет наблюдаться несколько промежуточных этапов по сравнению с кристаллами $\mathrm{LiNbO}_{3}: \mathrm{Mg}$. При концентрациях $0<[\mathrm{Zn}]<2.87 \mathrm{at} \%$ происходит плавное вытеснение дефектов $\mathrm{Nb}_{\mathrm{Li}}$ и $\mathrm{Li}$ с незначительным увеличением количества дефектов $\mathrm{V}_{\mathrm{Li}}[41,42]$. При концентрациях $2.87<[\mathrm{Zn}]<5.2 \mathrm{at} \%$ отсутствуют дефекты $\mathrm{Nb}_{\mathrm{Li}}$ и $\mathrm{V}_{\mathrm{Li}}$, выше $[\mathrm{Zn}]>5.2 \mathrm{at} \%$ происходит внедрение цинка уже в ниобиевые позиции с образованием дефектов $\mathrm{V}_{\mathrm{Nb}}[39,42,43]$.

Таким образом, в номинально чистых кристаллах $\mathrm{LiNbO}_{3}$ и легированных кристаллах $\mathrm{LiNbO}_{3}: \mathrm{Mg}(\mathrm{Zn})$ дефектная структура может описываться в рамках вакансионных сплит-моделей, за исключением модели кислородных вакансий. Преобладающей вакансионной моделью является модель литиевых вакансий, в которой на один избыточный атом ниобия (дефект $\mathrm{Nb}_{\mathrm{Li}}$ ) приходится четыре дефекта $\mathrm{V}_{\mathrm{Li}}$. Однако наиболее целесообразно рассматривать аддитивное действие обоих вакансионных моделей и учитывать роль не только $\mathrm{V}_{\mathrm{Li}}$, но и $\mathrm{V}_{\mathrm{Nb}}$ с учетом дефекта упаковки чередования основных катионов металлов вдоль полярной оси $c$. В легированных кристаллах при низких концентрациях легирующая примесь $\left(\mathrm{Zn}^{2+}, \mathrm{Mg}^{2+}\right)$ внедряется в позиции $\mathrm{Li}$, при пороговых значениях - в основные позиции $\mathrm{Nb}$.

\section{3. Люминесцентные свойства кристалла $\mathrm{LiNbO}_{3}$}

В современном оптическом материаловедении кристаллы $\mathrm{LiNbO}_{3}$ различного состава и генезиса можно применять для голографической записи информации, а также для нелинейного преобразования частоты лазерного излучения. Возможность записи голограммы зависит напрямую от фоторефрактивных свойств кристалла $\mathrm{LiNbO}_{3}$. В процессе записи происходит фотовозбуждение носителей заряда с глубоких уровней энергии (ловушек), и затем под действием диффузии и дрейфа они перемещаются из освещенной лазерным излучением области в неосвещенную область с последующим захватом на ловушках. При этом происходит запись голограммы за счет наведения поля пространственного заряда и соответственно изменение оптических свойств кристалла. Проблема заключается в чтении голограммы, так как происходит повторное воздействие лазерного излучения, что приводит к перераспределению заряда и тем самым стирается голографическая информация [44]. Частичное решение проблемы неразрушающего оптического считывания голограммы заключается, например, в двухступенчатой записи через промежуточное состояние с временем жизни, достаточным для создания необходимой заселенности этого уровня $[25,45,46]$, или считывании голограммы во внешнем магнитном поле за счет аномально высокого холловского фототока [47]. 
С другой стороны, фотоиндуцированное изменение показателей преломления приводит к искажениям фронта световой волны и нарушению генерации лазерного излучения в твердотельных лазерах на основе кристаллов ниобата лития, легированных редкоземельными элементами [48]. Далее рассмотрим процессы релаксации свободных носителей заряда с точки зрения исследований люминесцентных свойств кристаллов ниобата лития.

Согласно литературным источникам [49-52], люминесценция кристалла $\mathrm{LiNbO}_{3}$ наблюдается в видимой и ближней ИК областях оптического спектра. Спектральное распределение интенсивности свечения зависит от многих факторов, таких как стехиометрия [52,53], тип и концентрация легирующей примеси [53-56], условия отжига $[57,58]$, воздействие ионизирующего излучения [59,60], места возбуждения люминесценции [50,61], что изменяет механизмы дефектообразования, их распределение в решетке и зарядовое состояние некоторых переходных металлов без изменения их концентрации в кристалле $\mathrm{LiNbO}_{3}$ и, как следствие, каналы излучательной рекомбинации матрицы.

В работе [49] представлены некоторые качественные выводы относительно люминесценции кристаллов $\mathrm{LiNbO}_{3}$. Выявлено, что эмиссия в ближней ИК области спектра с максимумом при $840 \mathrm{~nm}(\Delta \lambda=200 \mathrm{~nm})$ не зависит от ориентации кристалла относительно падающего излучения (рубиновый лазер, $\lambda_{\mathrm{ex}}=696 \mathrm{~nm}$, возбуждение происходит с примесных уровней энергии и дислокаций), и интенсивность находится в прямой зависимости от длины кристалла [49]. Обнаружено, что при увеличении температуры от 294 до $526 \mathrm{~K}$ интенсивность люминесценции убывает по экспоненциальному закону. Энергия активации соответственно равна $E_{a}=0.28 \pm 0.03 \mathrm{eV}$. При этом ширина максимума не зависит от увеличения температуры. Выше $T>448 \mathrm{~K}$ люминесценция становиться очень слабой. Предполагается, что центры свечения, участвующие в излучательной рекомбинации, ответственны и за фоторефрактивные свойства, а характерное время затухания соответствует времени, за которое фотоэлектрон будет повторно захвачен на ловушке.

Дальнейшее развитие исследований люминесценции дано в работе [62]. В спектрах люминесценции кристалла $\mathrm{LiNbO}_{3}: \mathrm{Eu}^{3+}, \mathrm{Cr}^{3+}$ наблюдаются два широких максимума при 500 и $820 \mathrm{~nm}(\Delta \lambda=200$ и $150 \mathrm{~nm})$. Природа первого максимума соответствует излучению матрицы, а природа второго $-{ }^{4} T_{2}-{ }^{4} A_{2}$-переходами $(R$ линии) ионам $\mathrm{Cr}^{3+}$. С увеличением времени воздействия лазерного излучения $\left(\mathrm{N}_{2}\right.$-лазер, $\left.\lambda_{\mathrm{ex}}=337 \mathrm{~nm}\right)$ происходит перенос энергии между данными максимумами с преобладанием интенсивности в ближней ИК области спектра, при этом в переносе энергии не участвуют ионы $\mathrm{Eu}^{3+}$ [62] (рис. 2,a). Ионы $\mathrm{Cr}^{3+}$ размещаются в литиевых позициях, образуя $\mathrm{Cr}_{\mathrm{Li}}$-центр $[55,63,64]$. Данные центры зависят от локальных возмущений, которые создают $\mathrm{V}_{\mathrm{Li}}\left(\beta-\mathrm{Cr}_{\mathrm{Li}}\right), \mathrm{Nb}_{\mathrm{Li}}\left(\alpha-\mathrm{Cr}_{\mathrm{Li}}\right)$, а у $\gamma-\mathrm{Cr}_{\mathrm{Li}}$-центра в координационном окружении отсутствуют дефекты.
Характерная люминесценция в $\mathrm{LiNbO}_{3}: \mathrm{Cr}$ наблюдается при 13690, 13620 и $13540 \mathrm{~cm}^{-1}(730,734$ и $739 \mathrm{~nm})$ для $\beta-\mathrm{Cr}_{\mathrm{Li}}, \alpha-\mathrm{Cr}_{\mathrm{Li}}$ центров и $0-0$-электронного перехода [55]. Последний наблюдается только в кристалле $\mathrm{LiNbO}_{3}$, состав которого близок к стехиометрическому. В конгруэнтном кристалле происходит уширение $R$-линий $\mathrm{Cr}^{3+}$ в 2-2.5 раза относительно кристалла, полученном по VTE (Vapour Transport Equilibrium)технологии [65]. Однако люминесценция $\mathrm{Cr}^{3+}$-центров $\left(E<13650 \mathrm{~cm}^{-1}\right)$ подвергается температурному тушению вплоть до $T=60 \mathrm{~K}[55]$. В работе $[63,64]$ проведен тщательный анализ кинетико- люминесцентных характеристик градиентно-активированных кристаллов $\mathrm{LiNbO}_{3}: \mathrm{Cr}^{3+}: \mathrm{Mg}^{2+}$ (концентрация $\mathrm{Cr}^{3+} 0.05$ at\%) и установлено, что оптические центры $\mathrm{Cr}^{3+}$ могут встраиваться как в позиции лития, так и в позиции ниобия, при этом излучательные переходы в нормальных условиях $(T=300 \mathrm{~K})$ наблюдаются при 11363 и $10869 \mathrm{~cm}^{-1}(880$ и $920 \mathrm{~nm}$ ) для $\mathrm{Cr}_{\mathrm{Li}}$ и $\mathrm{Cr}_{\mathrm{Nb}}$ (рис. 2,b). Легирование $\mathrm{MgO}$ приводит к „красному“ смещению широких полос поглощения ${ }^{4} A_{2}-{ }^{4} T_{2}$ и ${ }^{4} A_{2}-{ }^{4} T_{1} \mathrm{Cr}^{3+}$, и увеличение концентрации $\mathrm{Mg} \mathrm{c} 1$ до $3 \mathrm{at} \%$ уменьшает поглощение ${ }^{4} A_{2}-{ }^{4} T_{2}$-полосы $[55,64]$. В спектре люминесценции наблюдаются помимо центров $\mathrm{Cr}_{\mathrm{Li}}$ полосы излучения при 13510 и $13565 \mathrm{~cm}^{-1}(740$ и $737 \mathrm{~nm})$, природа которых связана с $\mathrm{Cr}_{\mathrm{Nb}}$-центрами. Наличие дефекта $\mathrm{Mg}_{\mathrm{Li}}$ приводит к смещению пика люминесценции центра $\alpha$ $\mathrm{Cr}_{\mathrm{Li}}$, что говорит об изменении кристаллического поля (замена $\mathrm{Nb}_{\mathrm{Li}}$ на $\mathrm{Mg}_{\mathrm{Li}}$ ) [55]. Интересное предположение сделано в работе [64], при концентрации $[\mathrm{Mg}]>2 \mathrm{at} \%$, помимо локализации атомов $\mathrm{Mg}$ в позициях ниобия, происходит стимулирование излучательной рекомбинации центра $\mathrm{Cr}_{\mathrm{Nb}}$ за счет внедрения атома $\mathrm{Mg}$ в междоузлие.

Наши спектры фотолюминесценции номинально чистых кристаллов $\mathrm{LiNbO}_{3}$ показывают схожее люминесцентное гало в ближней ИК области спектра с более явными максимумами люминесценции при 763, 840, 920 и $996 \mathrm{~nm}$ (рис. 3). Обычно в данной области наблюдается широкая люминесцентная полоса с двумя перекрывающимися максимумами при 1.3 и $1.5 \mathrm{eV}(954$ и $827 \mathrm{~nm}$ ) [51]. Кроме того, провал при $823 \mathrm{~nm}\left(^{*}\right)$ может говорить о поглощении энергии другими центрами свечения. Аналогичные спектры фотолюминесценции получаются в кристаллах $\mathrm{LiNbO}_{3}$, легированных $\mathrm{Zn}$ или $\mathrm{Mg}$ (рис. 4). Возможно, что в процессе излучательной рекомбинации участвуют дополнительные центры свечения в виде поляронов малого радиуса, люминесценция которых также находится в ближней ИК области спектра. В другой работе [57] показано, что захват электрона с зоны проводимости дефектом $\mathrm{Nb}_{\mathrm{Li}}$ сопровождается излучением в ближней ИК области с максимумом при $850 \mathrm{~nm}$. В другой работе [66] пик люминесценции при $1.57 \mathrm{eV}(790 \mathrm{~nm})$ связан поляронной люминесценцией $\mathrm{Nb}_{\mathrm{Li}}^{4+}$, и его интенсивность пропорциональна концентрации $\mathrm{Nb}_{\mathrm{Li}}$ в кристалле $\mathrm{LiNbO}_{3}$. При этом исследование магнитного кругового дихроизма полосы поглощения при $1.6 \mathrm{eV}(776 \mathrm{~nm})$ показало, что ее природа связана 

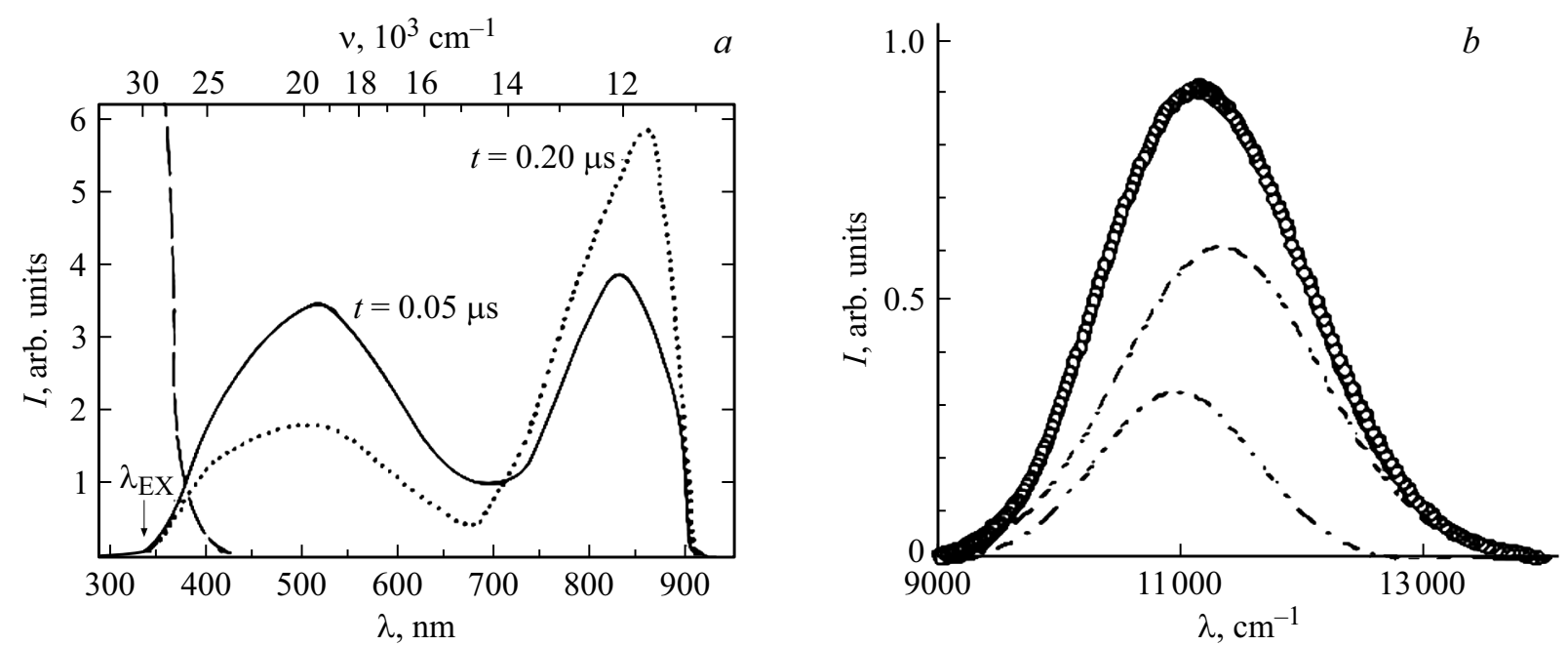

Рис. 2. $a-$ спектр поглощения (штриховая кривая) и спектры флуоресценции кристалла $\mathrm{LiNbO}_{3}: \mathrm{Eu}^{3+}, \mathrm{Cr}^{3+}$ при воздействии лазерного излучения $(337 \mathrm{~nm})$ в течени 0.05 и $0.20 \mu \mathrm{s}$ (сплошная, пунктирная кривые) при $T=300 \mathrm{~K}$ [42]; $b-$ спектр люминесценции кристалла $\mathrm{LiNbO}_{3}: \mathrm{Cr}, \mathrm{Mg}$ после разложения на две гауссовы составляющие: 11363 и $10869 \mathrm{~cm}^{-1}$ для $\mathrm{Cr}_{\mathrm{Li}}$ и $\mathrm{Cr}_{\mathrm{Nb}}[47]$.

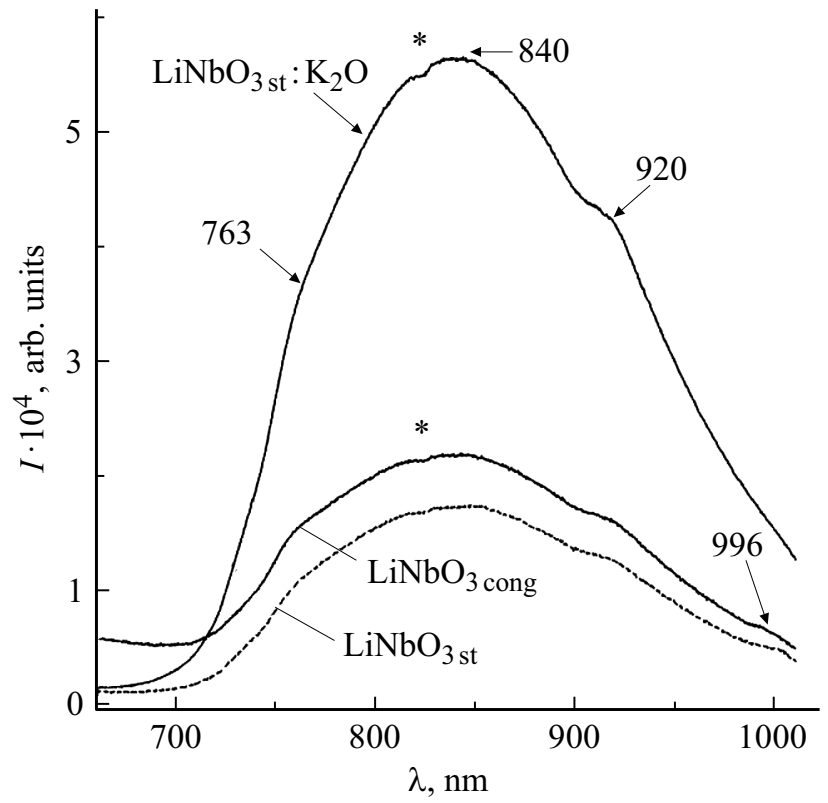

Рис. 3. Спектры фотолюминесценции номинально чистых кристаллов $\mathrm{LiNbO}_{3}$ в ближней ИК области спектра, $\lambda_{\mathrm{ex}}=325 \mathrm{~nm}$ и $T=300 \mathrm{~K}$.

с поляроном малого радиуса $\mathrm{Nb}_{\mathrm{Li}}^{4+}$ [67]. Действительно, уменьшение интенсивности максимума при $763 \mathrm{~nm}$ (рис. 3) наблюдается в спектре кристалла $\mathrm{LiNbO}_{3 \mathrm{st}}$

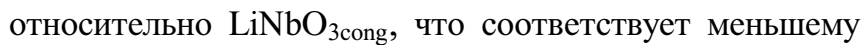
количеству точечных дефектов $\mathrm{Nb}_{\mathrm{Li}}$ в стехиометрическом кристалле. Вклад поляронной люминесценции $\mathrm{Nb}_{\mathrm{Li}}^{4+}$ в общий люминесцентный сигнал снижается при легировании $\mathrm{Mg}$ (5.29 и $5.91 \mathrm{~mol} \%$ ) или $\mathrm{Zn} \mathrm{(0.07-2.01}$ и $6.50 \mathrm{~mol} \%$ ) кристаллов $\mathrm{LiNbO}_{3}$ (рис. 4).
Кроме того, термическая обработка в воздушной атмосфере приводит к обогащению приповерхностной области кристалла дефектами $\mathrm{Nb}_{\mathrm{Li}}$, что усиливает поляронную люминесценцию [57]. При легировании поверхности кристалла $\mathrm{LiNbO}_{3}: \mathrm{Fe}$ происходит тушение поляронной люминесценции, так как происходит вытеснение из позиций лития избыточных катионов $\mathrm{Nb}^{5+}[57,66]$. При $[\mathrm{Fe}]=1 \mathrm{at} \%$ в кристалле $\mathrm{LiNbO}_{3}: \mathrm{Fe}$ интегральная интенсивность поляронной люминесценции $\mathrm{Nb}_{\mathrm{Li}}$ падает на 50\% [66]. Ионы $\mathrm{Fe}^{2+}$ представляют донорные центры, и их характерная полоса поглощения наблюдается при $2.66 \mathrm{eV}(467 \mathrm{~nm})$, интенсивность которой пропорциональна концентрации $\left[\mathrm{Fe}^{2+}\right][56,68]$. После фотовозбуждения ионов $\mathrm{Fe}^{2+}$ электрон может быть повторно захвачен на $\mathrm{Fe}^{3+}$ или локализоваться на дефекте $\mathrm{Nb}_{\mathrm{Li}}$ с образованием полярона малого радиуса, что приводит к увеличению поляронной люминесценции $\mathrm{Nb}_{\mathrm{Li}}$ [56]. Однако в исследуемых кристаллах $\mathrm{LiNbO}_{3}$ примесь $\mathrm{Fe}^{2+}$ находится в следовых количествах $\left(10^{-3} \mathrm{~mol} \%\right)$, что затрудняет анализ его влияния на процессы релаксации электронных возбуждений, и ее влияние минимально.

По аналогии со схожими механизмами излучательной рекомбинации в кристаллах $\mathrm{CaWO}_{4}$ и $\mathrm{YVO}_{4}$ можно предположить, что люминесценция кристаллов $\mathrm{LiNbO}_{3}$ в видимом диапазоне связана с кислороднооктаэдрическими кластерами $\mathrm{NbO}_{6}$. Тщательный анализ ЭПР данных [69] показал, что электроны локализуются на ионах $\mathrm{Nb}^{5+}$ в основных позициях с образованием полярона малого радиуса („free polaron“) $-\mathrm{Nb}_{\mathrm{Nb}}^{4+}$, a дырки претерпевают захват на акцепторных центрах, предположительно, на ионах $\mathrm{O}^{-}$(„free hole polaron“). В процессе возбуждения электрон переходит из молекулярной орбитали $2 p-\mathrm{O}$ на молекулярную орбиталь $t_{2 g}$ иона $\mathrm{Nb}^{5+}[62]$. Стоксов сдвиг равен $15700 \mathrm{~cm}^{-1}$ 

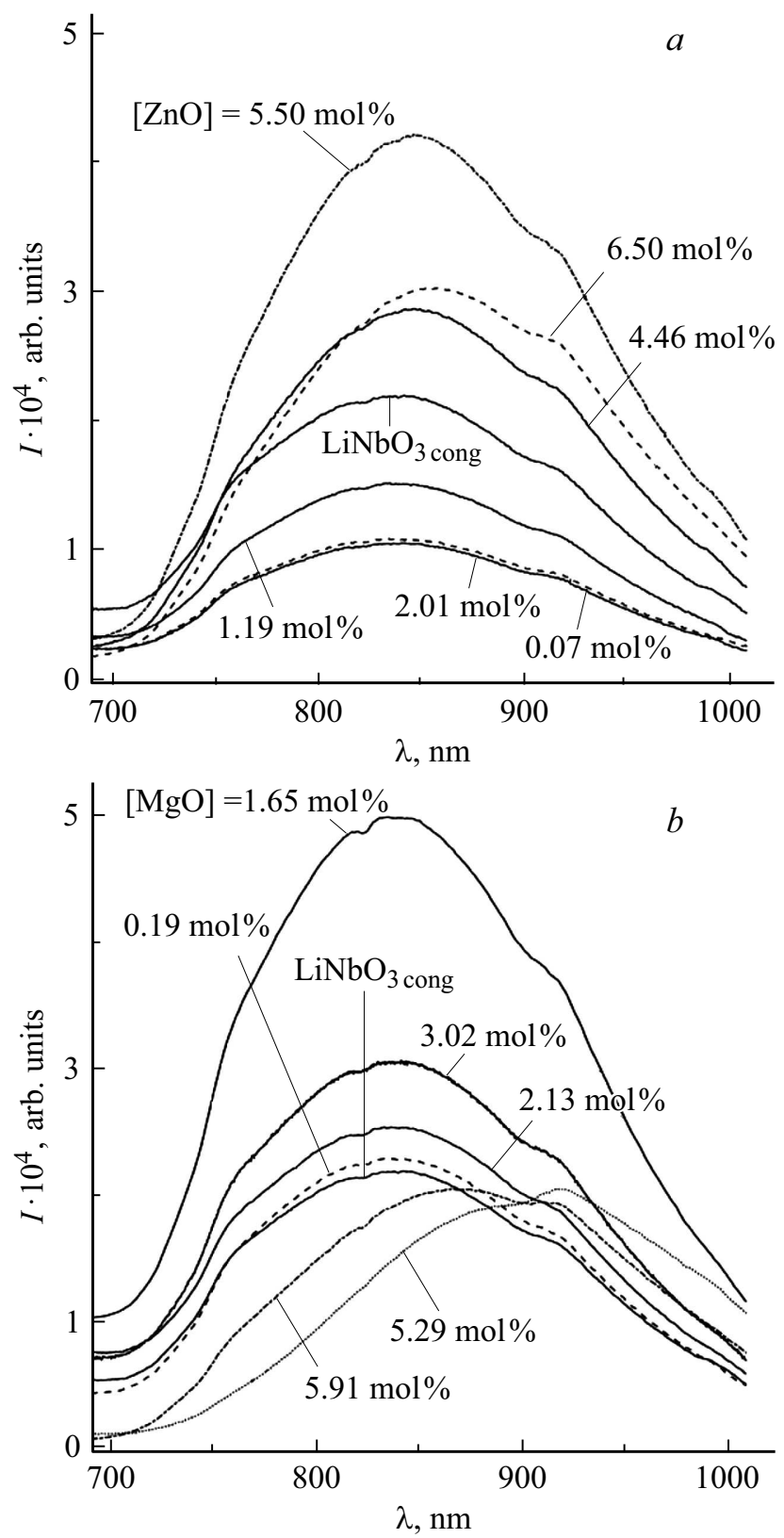

Рис. 4. Спектры фотолюминесценции кристаллов $\mathrm{LiNbO}_{3}: \mathrm{Zn}(a)$ и $\mathrm{LiNbO}_{3}: \mathrm{Mg}(b)$ в ближней ИК области спектра, $\lambda_{\mathrm{ex}}=325 \mathrm{~nm}$ и $T=300 \mathrm{~K}$.

для максимума при $500 \mathrm{~nm}[70,71]$. При этом время затухания не зависит от температуры $(T=14-300 \mathrm{~K})$ и составляет $0.22 \mu \mathrm{s}$, что указывает на глубокую электронную ловушку. Образование дырочных центров захвата $\mathrm{O}^{-}$, которые находятся вблизи литиевых вакансий („bound hole polaron“), сопровождается увеличением коэффициента поглощения в видимой области при $2.5 \mathrm{eV}$ $(496 \mathrm{~nm})[72,73]$. При комнатной температуре или под действием интенсивного освещения наблюдается слабое поглощение данного центра, что, возможно, обусловлено рекомбинационными процессами с поляронами малого радиуса $[74,75]$. В работах $[59,76,77]$ электронно- дырочная рекомбинация между $\mathrm{Nb}_{\mathrm{Nb}}^{4+}$ и $\mathrm{O}^{-}$наблюдается при $2.82-2.6 \mathrm{eV}(440-477 \mathrm{~nm})$.

Исследование эволюции спектра фотолюминесценции кристаллов $\mathrm{LiNbO}_{3}: \mathrm{Mg}([\mathrm{Mg}]=3$ и $7 \mathrm{~mol} \%)$ во времени (time-resolved photoelectron spectroscopy), показывает распределение интенсивности свечения $I(t, \lambda)$ с максимумом при $2.62 \mathrm{eV}(474 \mathrm{~nm})$ в спектральном диапазоне от 400 до $650 \mathrm{~nm}$ и в диапазоне с временным разрешением от $10^{-9}$ до $6 \cdot 10^{-6} \mathrm{~s}$ при $T=150 \mathrm{~K}$ [78]. Авторы предполагают, что фотолюминесценция при $2.62 \mathrm{eV}$ является результатом поляронной рекомбинации $\mathrm{Nb}_{\mathrm{Nb}}^{4+}$ и $\mathrm{O}^{-}$. При этом кинетика затухания данной полосы излучения описывается двумя экспоненциальными функциями. Для кристалла $\mathrm{LiNbO}_{3} \mathrm{c}[\mathrm{Mg}]=7 \mathrm{~mol} \%$ величины длительности свечения $\tau_{1}=12 \mu \mathrm{s} \mathrm{и} \tau_{2}=1.1 \mathrm{~s}$, а с $[\mathrm{Mg}]=3 \mathrm{~mol} \%-$ $\tau_{1}=2 \mu \mathrm{s}$ и $\tau_{2}=0.1 \mathrm{~ms}$ [78]. Рекомбинация с перескоком в одном месте (с одного узла кристаллической решетки на другой) дает быструю релаксацию, тогда как медленная релаксация может быть объяснена насыщением ловушек, что приводит к прыжковой проводимости поляронов („hopping“). Разница между длительностями свечения в зависимости от концентрации $\mathrm{Mg}$ обусловлена локальными искажениями кристаллической решетки дефектами $\mathrm{Mg}_{\mathrm{Nb}}$ в кристалле $\mathrm{LiNbO}_{3}([\mathrm{Mg}]=7 \mathrm{~mol} \%)$ и изменением поляронной проводимости [78]. В другой работе [52] выявлены две отчетливые компоненты затухания люминесценции в пикосекундном диапазоне. Изменение состава кристалла (стехиометрии и/или концентрации легирующей примеси $\mathrm{Mg}$ ) в значительной степени влияет на более продолжительную компоненту длительности свечения. Так, близкий к стехиометрическому составу кристалл $([\mathrm{Li}] /[\mathrm{Nb}] \approx 1)$, полученный по технологии HTTSSG, и кристалл, легированный $1 \mathrm{~mol} \%$ $\mathrm{Mg}$, имеют сопоставимые по величине длительности свечения. В конгруэнтном кристалле преобладает короткая компонента затухания, а легирование $\mathrm{Mg}$ приводит к увеличению продолжительной компоненты длительности свечения. Наличие обеих компонент затухания обсуждается авторами на основе модели автолокализованных экситонов $[52,79]$. Предложено, что короткая компонента обусловлена синглетным состоянием экситонов, которые не могут мигрировать через кристаллическую решетку из-за очень короткого собственного времени жизни, а продолжительная компонента обусловлена триплетным состоянием экситонов, рекомбинация которых наблюдается вблизи дефектных центров.

Стоит отметить, что положение максимума люминесценции матрицы в видимой области спектра зависит от стехиометрии и состояния образца. Так, керамика на основе смеси $\mathrm{Nb}_{2} \mathrm{O}_{5}$ и $\mathrm{Li}_{2} \mathrm{CO}_{3}$ с избытком последнего в $2 \mathrm{~mol} \%$ показывает интенсивную люминесценцию в видимой области спектра при $440 \mathrm{~nm}$ при $T=5 \mathrm{~K}$ и не зависит от длины волны источника возбуждения [59,77]. По мере уменьшения температуры окружающей среды интенсивность люминесценции увеличивается, при комнатной температуре она практически полностью тушится. С избытком $\mathrm{Nb}_{2} \mathrm{O}_{5}$ в $2 \mathrm{~mol} \%$ в спектре наблюдается 

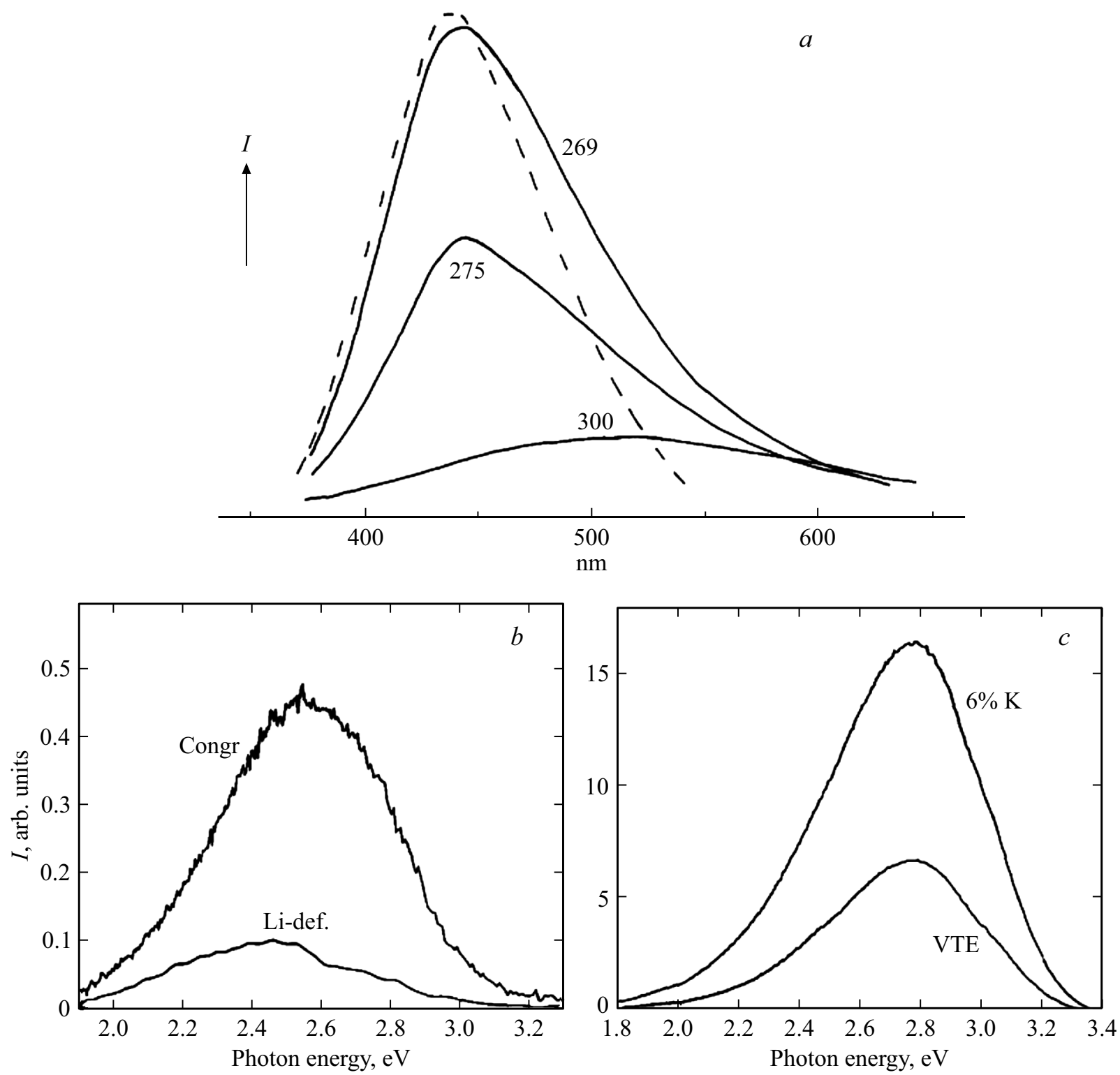

Рис. 5. $a$ - спектры фотолюминесценции кристалла $\mathrm{LiNbO}_{3 \mathrm{st}}$ при $T=4.2 \mathrm{~K}$ при возбуждающем излучении $\lambda_{\mathrm{ex}}=269$, 275 и $300 \mathrm{~nm}$ в сравнении со спектром порошкового $\mathrm{LiNbO}_{3 \mathrm{st}}$ (штриховая линия) [51]; $b, c$ - спектры фотолюминесценции кристаллов $\mathrm{LiNbO}_{3 \text { cong }}, \mathrm{LiNbO}_{3}$, выращенных из расплава с 47 mol\% $\mathrm{Li}_{2} \mathrm{O}$ (Li-def), и $\mathrm{LiNbO}_{3 \mathrm{st}}$, полученного по технологии VTE (vapor transport equilibration), и кристалла $\mathrm{LiNbO}_{3 \mathrm{st}}: \mathrm{K}_{2} \mathrm{O}$ при $\lambda_{\mathrm{ex}}=270 \mathrm{~nm}$ и $T=80 \mathrm{~K}$ [52].

два максимума при 440 и $520 \mathrm{~nm}$, причем последний наблюдается только при возбуждении с $\lambda_{\mathrm{ex}}=320 \mathrm{~nm}$. В кристалле $\mathrm{LiNbO}_{3 \text { cong }}$ в поликристаллическом состоянии наблюдается только одна широкая полоса люминесценции при $520 \mathrm{~nm}$. Максимум при $440 \mathrm{~nm}$ связывают с излучательной рекомбинацией между $\mathrm{Nb}_{\mathrm{Nb}}^{4+}$ и $\mathrm{O}^{-}$в основном ниобиевом октаэдре, так как время затухания совпадает с характеристическими временами для ниобиевой группы в других соединениях [59]. Максимум при $520 \mathrm{~nm}$ авторы связывают с наличием дефектов $\mathrm{Nb}_{\mathrm{Li}} \mathrm{c}$ временем затухания порядка $0.08 \mu \mathrm{s}$. В работе [80] представлено сравнение спектра фотолюминесценции кристалла $\mathrm{LiNbO}_{3 \text { st }}$ в поликристаллическом состоянии со спектром самого кристалла и исследована зависимость интенсивности последнего от параметров возбуждающего излучения (рис. 5,a). Отличие заключается лишь в наличии дополнительной излучательной рекомбинации в длинноволновой области спектра. Увеличение $\lambda_{\mathrm{ex}}$ с 269 до $300 \mathrm{~nm}$ приводит к смещению люминесцентного гало с 440 на $520 \mathrm{~nm}$, что говорит о наличии двух центров свечения: $\mathrm{Nb}_{\mathrm{Nb}}^{4+}-\mathrm{O}^{-}$и $\mathrm{Nb}_{\mathrm{Li}}^{4+}-\mathrm{O}^{-}$(рис. 5,a). Схожие выводы получены в работе [53]: увеличение стехиометрии приводит к смещению люминесценции в коротковолновую область спектра (рис. 5, $b, c$ ). Кроме того, при $\lambda_{\mathrm{ex}}=320 \mathrm{~nm}$ благодаря большей проникающей способности происходит возбуждение люминесценции с 

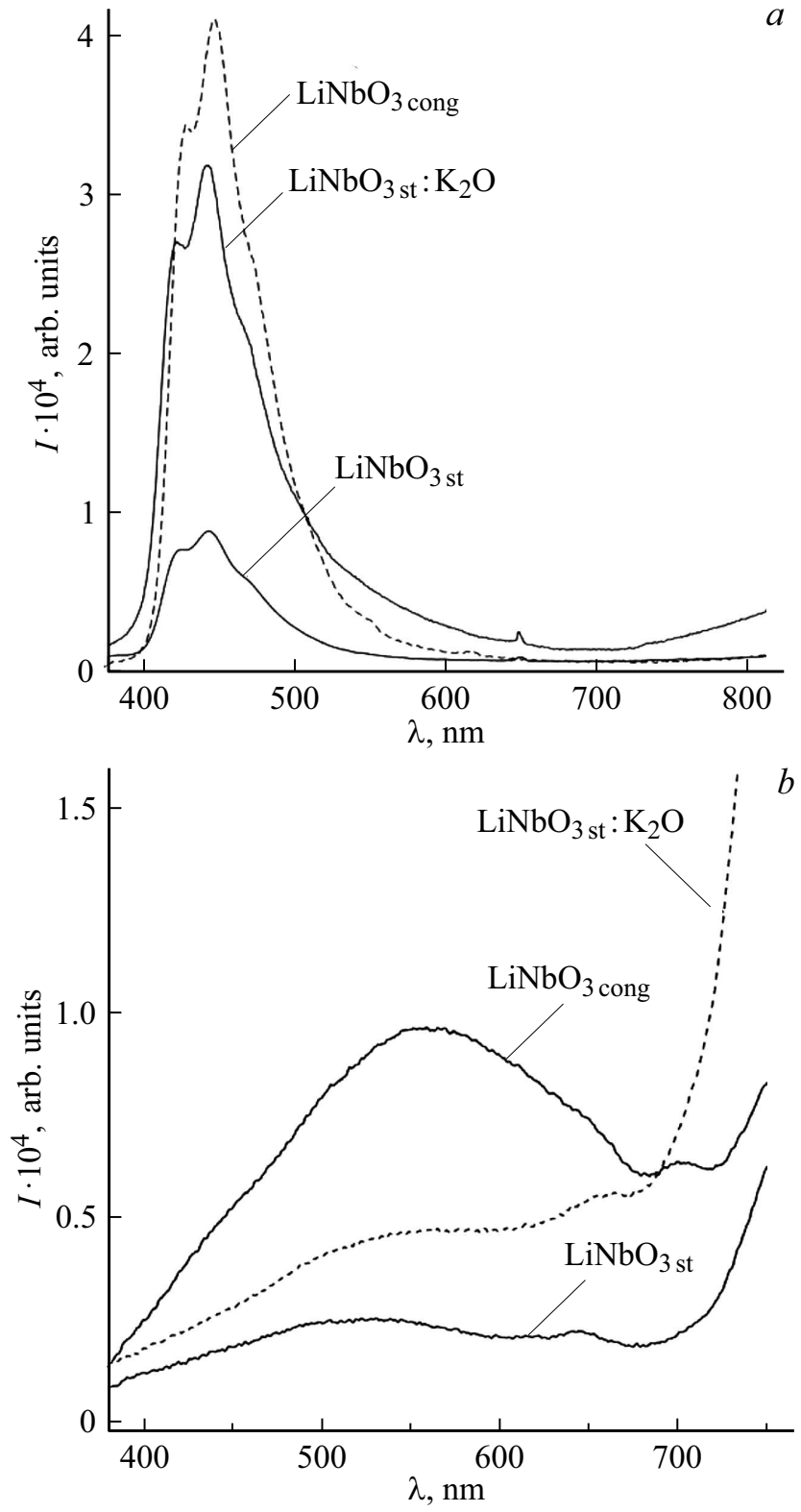

Рис. 6. Спектры фотолюминесценции с поверхности $(a)$ и объема $(b)$ номинально чистых кристаллов $\mathrm{LiNbO}_{3}$ в видимой области спектра, $\lambda_{\mathrm{ex}}=325 \mathrm{~nm}$ и $T=300 \mathrm{~K}$.

объема кристалла. На рис. 6 представлены экспериментальные спектры фотолюминесценции объема и поверхностных дефектов в виде трещин, сколов кристаллов $\mathrm{LiNbO}_{3 \text { cong }}, \mathrm{LiNbO}_{3 \mathrm{st}}, \mathrm{LiNbO}_{3 \mathrm{st}}: \mathrm{K}_{2} \mathrm{O}$. В работе [81] показано, что на поверхности кристалла доминирующие центры свечения при 423 и 443 nm связаны с излучательной рекомбинацией между электронно-дырочными парами $\mathrm{Nb}_{\mathrm{Nb}}^{4+}-\mathrm{O}^{-}$в основном $\mathrm{NbO}_{6}$, так как, возможно, происходит снятие вырождения $5 d$-уровней $\mathrm{Nb}$ за счет наличия двух различных расстояний между центральным ионом $\mathrm{Nb}$ и окружающими его кислородами (1.879 и $2.126 \AA)$. Такая особенность может приводить к расщеплению энергетических уровней $\mathrm{Nb}$ в кристаллическом поле искаженного кислородно-октаэдрического кластера $\mathrm{NbO}_{6}$ подобно ян-теллеровскому иону $\mathrm{Fe}^{2+}$ в лигандном окружении в виде октаэдров ионов $\mathrm{O}^{2-}[56,82]$. Кроме того, изменение поляризуемости кластеров $\mathrm{NbO}_{6}$ также должно влиять на изменение уровней энергии дефектов $\mathrm{Nb}_{\mathrm{Li}}$. Центры люминесценции с участием точечных дефектов $\mathrm{V}_{\mathrm{Li}}$ и $\mathrm{Nb}_{\mathrm{Li}}$ излучают при 495 и $532 \mathrm{~nm}$ на основании данных по [80,83]. При этом в окрестности дефекта $\mathrm{V}_{\mathrm{Li}}$ образуется связанный полярон малого радиуса $\mathrm{O}^{-}$[72]. Согласно модели литиевых вакансий и отношения интенсивности полос излучения, на поверхности кристалла $\mathrm{LiNbO}_{3 \text { cong }}$ присутствуют одновременно дефекты $\mathrm{V}_{\mathrm{Li}}$ и $\mathrm{V}_{\mathrm{Nb}}$, а в кристалле $\mathrm{LiNbO}_{\mathrm{st}}$ в основных позициях лития, кроме того, присутствуют дополнительные неактивные примесные ионы, которые увеличивают избыток дефектов $\mathrm{V}_{\mathrm{Li}}$ [81]. Квантово-механический расчет электронной структуры ниобата лития показал, что возможно существование дефекта в виде стабильной биполяронной пары $\mathrm{Nb}_{\mathrm{Nb}}^{4+}-\mathrm{Nb}_{\mathrm{Li}}^{4+}$, оптические переходы которой находятся в видимой области спектра при 2.3 и $2.0 \mathrm{eV}(540$ и $620 \mathrm{~nm})$ [84]. В спектре восстановленного кристалла $\mathrm{LiNbO}_{3}$ наблюдается широкая полоса поглощения при $2.5 \mathrm{eV}(500 \mathrm{~nm})$, которая обусловлена образованием стабильной биполяронной пары $\mathrm{Nb}_{\mathrm{Nb}}^{4+}-\mathrm{Nb}_{\mathrm{Li}}^{4+}[56,85]$. По мере увеличения температуры $(T=122-575 \mathrm{~K})$ происходит постепенная термическая диссоциация биполяронных пар на отдельные поляроны малого радиуса (при повторном захвате электронов) $\mathrm{Nb}_{\mathrm{Nb}}^{4+}$ и $\mathrm{Nb}_{\mathrm{Li}}^{4+}$. Поглощение последнего наблюдается в области $1.6 \mathrm{eV}(760 \mathrm{~nm})$ [85]. Роль объемных дефектов (рис. $5, b)$ описана в работе [50]. На основании литературных данных было проведено разложение спектра на составляющие с точки зрения точечных дефектов, являющихся центрами свечения, и было установлено, что в объеме кристалла $\mathrm{LiNbO}_{3 \text { cong }}$ доминирующими центрами свечения являются центры с участием дефектов $\mathrm{Nb}_{\mathrm{Li}}$, в то время как в объеме кристаллов $\mathrm{LiNbO}_{3 \mathrm{st}}$ и $\mathrm{LiNbO}_{3 \mathrm{st}}: \mathrm{K}_{2} \mathrm{O}$ практически отсутствует люминесценция данных центров свечения.

При возбуждении люминесценции рентгеновским излучением в кристалле $\mathrm{LiNbO}_{3 \text { cong в }}$ отличие от работы [59] авторы работы [77] наблюдали максимум при $425 \mathrm{~nm}$, который, по их мнению, связан с кластером $\mathrm{NbO}_{6}$. Кроме того, при $520 \mathrm{~nm}$ наблюдается очень слабая излучательная рекомбинация, что объясняется более сильным проникновением рентгеновских лучей в объем кристалла по сравнению УФ излучением. Исследования катодолюминесценции в кристалле $\mathrm{LiNbO}_{3}$ после термической обработки в атмосфере водорода при $1173 \mathrm{~K}$ в течение $45 \mathrm{~h}$ показывают в спектре три явных максимума при 410, 525 и $580 \mathrm{~nm}$, интенсивность которых изменяется в ряде $I_{525}>I_{580}>I_{410}$. Природу максимума при $525 \mathrm{~nm}$ сравнивают с сильным нарушением стехиометрии на поверхности кристалла из-за десорбции $\mathrm{Li}_{2} \mathrm{O}$ в процессе термообработки. Кроме того, в месте механического воздействия после вдавливания наблюдается 


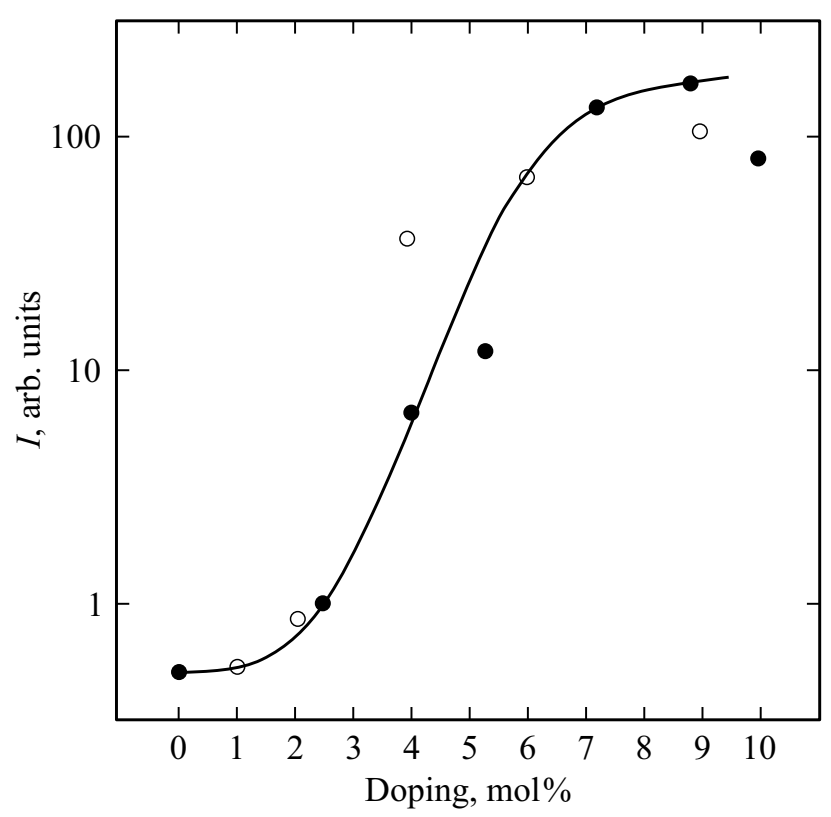

Pис. 7. Зависимость интегральной интенсивности спектра фотолюминесценции от концентрации легирующей примеси: $\mathrm{Zn}(\bullet)$ и $\mathrm{Mg}\left(\right.$ ( ) при $\lambda_{\mathrm{ex}}=270 \mathrm{~nm}$ и $T=80 \mathrm{~K}[52]$.

интенсивная катодолюминесценция с максимумом при $800 \mathrm{~nm}$ в ближнем ИК диапазоне [60].

Вакуумный отжиг $\left(>700^{\circ} \mathrm{C}\right)$ приводит к возникновению кислородных вакансий, которые ответственны за полосу поглощения в видимой области спектра и черную окраску кристалла $\mathrm{LiNbO}_{3}$ [58]. Воздействие излучения ксеноновой лампы мощностью $150 \mathrm{~W}$ при $80 \mathrm{~K}$ на восстановленный кристалл $\mathrm{LiNbO}_{3}$ приводит к смещению максимума поглощения от 500 к $760 \mathrm{~nm}$ в ближней ИК области. Это происходит из-за отрыва электрона от $F$-центра и последующего захвата на $d$-уровни $\mathrm{Nb}^{4+}$. Последующее поглощение при $760 \mathrm{~nm}$ обусловлено $F^{+}$центрами. Нагрев до комнатной температуры ведет к „стиранию“ полосы поглощения при $760 \mathrm{~nm}$ и сигнала от $\mathrm{Nb}^{4+}$ в спектре ЭПР [54]. Облучение потоком электронов при $77 \mathrm{~K}$ приводит к образованию дырочных центров захвата в виде $\mathrm{O}^{-}$, и спектр поглощения совпадает со спектром поглощения $F$-центра.

В легированных кристаллах $\mathrm{LiNbO}_{3}: \mathrm{Zn}$ и $\mathrm{LiNbO}_{3}: \mathrm{Mg}$ наблюдается увеличение интегральной интенсивности свечения в видимой области по мере увеличения концентрации легирующей примеси $[53,54]$ (рис. 7). Разложения спектров на низкоэнергетическую и высокоэнергетическую компоненты с максимумами при 2.3 и $2.7 \mathrm{eV}(540$ и $460 \mathrm{~nm})$ позволило установить, что по мере увеличения концентрации легирующей примеси происходит увеличение интенсивности высокоэнергетической компоненты, что соответствует увеличению отношения $[\mathrm{Li}] /[\mathrm{Nb}][53]$. При этом дополнительных полос излучения не наблюдается во всем концентрационном диапазоне легирующих примесей $[53,54,86]$. В наших кристаллах $\mathrm{LiNbO}_{3}: \mathrm{Zn}$ в аналогичных спектрах фотолю-
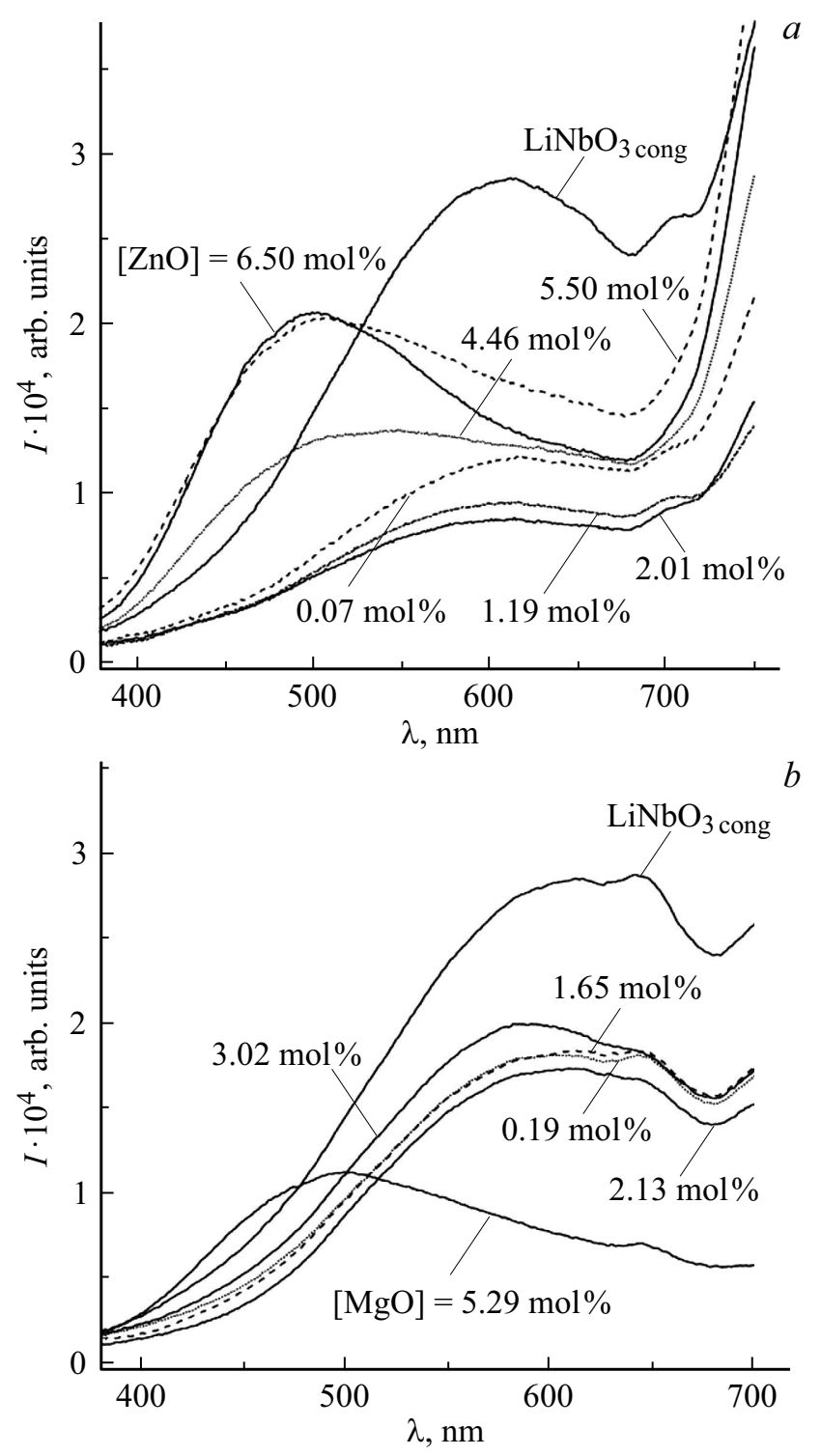

Рис. 8. Спектры фотолюминесценции кристаллов $\mathrm{LiNbO}_{3}: \mathrm{Zn}(a)$ и $\mathrm{LiNbO}_{3}: \mathrm{Mg}(b)$ в видимой области спектра, $\lambda_{\mathrm{ex}}=325 \mathrm{~nm}$ и $T=300 \mathrm{~K}$.

минесценции нет дополнительных полос излучения при концентрации $[\mathrm{ZnO}]<4.46 \mathrm{~mol} \%$ и $[\mathrm{MgO}]<5.29 \mathrm{~mol} \%$ (рис. 8). Обнаружено, что с увеличением концентрации цинка от 0.07 до $2.01 \mathrm{~mol} \% \mathrm{ZnO}$ наблюдается уменьшение интенсивности полос люминесценции, обусловленных собственными дефектами, за счет вытеснения дефектов $\mathrm{Nb}_{\mathrm{Li}}$ и уменьшения при этом концентрации дефектов $\mathrm{V}_{\mathrm{Li}}$, что говорит об увеличении соотношения $[\mathrm{Li}] /[\mathrm{Nb}]$. Так как в нашем случае фотолюминесцирует объем кристаллов, то доминирующая полоса в высокоинтенсивной части спектра не наблюдается. С приближением состава кристалла ко второму концентрационному порогу ( $\approx 7.0 \mathrm{~mol} \% \mathrm{ZnO}$ ) происходит смещение люминесцентного гало на $\approx 0.41 \mathrm{eV}$ в высокоэнергетическую область спектра и увеличение интенсивности 
центров свечения с максимумами при 2.66 и $2.26 \mathrm{eV}$ $(466$ и $549 \mathrm{~nm})$, обусловленные возможным появлением точечных дефектов $\mathrm{Zn}_{\mathrm{Nb}}$ [42]. Эффект смещения можно также объяснить с точки зрения зонных представлений сегнетополупроводников [87]. По мере увеличения концентрации $\mathrm{Zn}$ растет концентрация дефектов $\mathrm{Zn}_{\mathrm{Li}}$, которые, согласно работе [88] и нашим исследования [61], выступают в качестве мелких донорных уровней энергии. При высоких концентрациях $\mathrm{Zn}$ должно происходить заполнение энергетических зон вблизи дна зоны проводимости (эффект Бурштейна-Мосса [89]), тем самым увеличивается ширина запрещенной зоны и спектры люминесценции должны претерпевать „синее“ смещение. Из-за схожего механизма вхождения легирующих примесей $\mathrm{Zn}$ и $\mathrm{Mg}$ можно предположить схожее поведение фотолюминесценции в спектрах исследуемых кристаллах. Так, легирование $\mathrm{Mg}$ приводит к снижению интенсивности излучательной рекомбинации в видимой области спектра (рис. 4) за счет внедрения в позиции $\mathrm{Li}$ и уменьшения числа дефектов $\mathrm{Nb}_{\mathrm{Li}}$. При $[\mathrm{MgO}]=0.89 \mathrm{~mol} \%$ люминесцентное гало смещается в „синюю“ область спектра, что может говорить о достижении порогового значения, при котором Mg встраивается в основные позиции $\mathrm{Nb}$. Стоит отметить, что смещение наблюдается в ближней ИК области спектра при $[\mathrm{ZnO}]>4.46 \mathrm{~mol} \%$ и $[\mathrm{MgO}]>5.29 \mathrm{~mol} \%$ только в длинноволновую область спектра (рис. 3).

\section{Заключение}

Таким образом, благодаря многофакторному воздействию на люминесцентные свойства кристаллов $\mathrm{LiNbO}_{3}$ различного состава и генезиса, характеризующихся сложным спектром дефектов, наличию в структуре кристалла искаженных кислородно-октаэдрических кластеров различного вида $\left(\mathrm{MeO}_{6}, \mathrm{Me}=\mathrm{Nb}, \mathrm{Li}\right.$, примесный катион), происходит перекрывание спектров люминесценции от различных точечных дефектов. При этом происходят электрон-фононные взаимодействия, перенос энергии и изменяется влияние кристаллического поля на люминесценцию. Такая многофакторность усложняет выделение центров свечения и выявление их природы. Несомненно, что люминесценцию в кристалле ниобата лития можно разделить на три области: коротковолновую $(400-500 \mathrm{~nm})$ и длинноволновую $(500-620 \mathrm{~nm})$ области в видимом диапазоне и ближнюю ИК область. В коротковолновой области спектра люминесцируют преимущественно электронно-дырочные пары $\mathrm{Nb}_{\mathrm{Nb}}^{4+}-\mathrm{O}^{-}$, в длинноволновой области спектра активны центры свечения, связанные с нарушением стехиометрии вследствие наличия точечных $\mathrm{Nb}_{\mathrm{Li}}$ и $\mathrm{V}_{\mathrm{Li}}$ и комплексных дефектов. Природа поляронных дефектов, люминесцирующих в ближней ИК области спектра, обусловлена несколькими центрами свечения: точечными дефектами $\mathrm{Cr}_{\mathrm{Nb}}$ и $\mathrm{Cr}_{\mathrm{Li}}$ в следовых количествах и поляронами малого радиуса $\mathrm{Nb}_{\mathrm{Li}}$. Слабая люминесценция с объема кристаллов в видимой области спектра по сравнению с поляронной люминесценцией в ближней ИК областьи обусловлена за счет переноса энергии между центрами свечения. В легированных кристаллах $\mathrm{LiNbO}_{3}: \mathrm{Zn}$ и $\mathrm{LiNbO}_{3}: \mathrm{Mg}$ люминесценция зависит от концентрации легирующей примеси и с увеличением концентрации $\mathrm{ZnO}$ до $4.46 \mathrm{~mol} \%$ и $\mathrm{MgO}$ до $5.29 \mathrm{~mol} \%$ происходит тушение свечения собственных дефектов $\left(\mathrm{Nb}_{\mathrm{Li}}, \mathrm{V}_{\mathrm{Li}}\right.$, $\left.\mathrm{Nb}_{\mathrm{Nb}}-\mathrm{Nb}_{\mathrm{Li}}\right)$. Дальнейшее повышение концентрации легирующей примеси приводит смещению люминесцентного гало в „синюю“ область спектра за счет изменения механизма вхождения легирующей примеси в решетку кристалла.

\section{Благодарность}

Авторы выражают благодарность В.Б. Пикулеву за помощь в постановке эксперимента по фотолюминесценции и обсуждение экспериментальных данных.

\section{Финансирование работы}

Работа была выполнена в рамках государственного задания Министерства науки и высшего образования РФ (тема № 0226-2018-0004, регистрационный номер AАAА-A18-118022190125-2) и при частичной финансовой поддержке РФФИ (грант „Аспиранты“ № 20-3390078).

\section{Конфликт интересов}

Авторы заявляют, что у них нет конфликта интересов.

\section{Список литературы}

[1] Ю.С. Кузьминов. Электрооптический и нелинейнооптический кристалл ниобата лития (Наука, М., 1987), c. $9-24$.

[2] М.Н. Палатников, Н.В. Сидоров, О.В. Макарова, И.В. Бирюкова. Фундаментальные аспекты технологии сильно легированных кристаллов ниобата лития (Апатиты: КНЦ РАН, 2017).

[3] Venkatraman Gopalan, T.E. Mitchell, Y. Furukawa, K. Kitamura. Appl. Phys. Lett., 72 (16), 1981 (1998). DOI: $10.1063 / 1.121491$

[4] Н.В. Сидоров, Н.А. Теплякова, Л.А. Бобрева, M.H. Палатников. ЖСX, 60 (11), 1837(2019). DOI: $10.26902 / J S C \_i d 49954$ [N.V. Sidorov, N.A. Teplyakova, L.A. Bobreva, M.N. Palatnikov. J. Struct. Chem., 60 (11), 1765 (2019). DOI: 10.1134/S002247661911009X]

[5] Н.В. Сидоров, О.Ю. Пикуль, А.А. Крук, Н.А. Теплякова, А.А. Яничев, М.Н. Палатников. Опт. и спектр., 118 (2), 273 (2015). DOI: 10.7868/S0030403415020178 [N.V. Sidorov, A.A. Kruk, N.A. Teplyakova, A.A. Yanichev, M.N. Palatnikov, O.Y. Pikoul. Opt. Spectr., 118(2), 259 (2015). DOI: 10.1134/S0030400X15020174]

[6] Н.А. Теплякова, Н.В. Сидоров, М.Н. Палатников. Перспективные материалы, 4, 19 (2016). 
[7] Yuinlin Chen, Weiguo Yan, Juan Guo, Shaolin Chen, Guangyin Zhang. Appl. Phys. Lett., 87 (21), 212904 (2005). DOI: $10.1063 / 1.2135389$

[8] S. Kumaragurubaran, S. Takekawa, M. Nakamura, S. Ganesamoorthy, K. Terabe, K. Kitamura. In: Conference on Lasers and Electro-Optics/Quantum Electronics and Laser Science and Photonic Applications Systems Technologies, Technical Digest (CD) (Optical Society of America, 2005), p. 393.

[9] В.Я. Шур, Е.Л. Румянцев, Р.Г. Бачко, Г.Д. Миллер, М.М. Фейер, Р.Л. Байер. ФТТ, 41 (10), 1831 (1999).

[10] Donghwa Lee, Venkatraman Gopalan, S.R. Phillpot. Appl. Phys. Lett., 109 (8), 082905 (2016). DOI: 10.1063/1.4961614

[11] V. Kemlin, D. Jegouso, J. Debray, E. Boursier, P. Segonds, B. Boulanger, H. Ishizuki, T. Taira, G. Mennerat, J.-M. Melkonian, A. Godard. Opt. Express, 21 (23), 28886 (2013). DOI: 10.1364/OE.21.028886

[12] Kaili Zhai, Shuanggen Zhang, Xiurong Ma, Youjian Song, Minglie Hu, Qingyue Wang, Kailiang Zhang. IEEE Photonics J., 8 (2), 7802307 (2016). DOI: 10.1109/JPHOT.2016.2536364

[13] Dong Zhou Wang, De Hui Sun, Xue Liang Kang, Yuan Hua Sang, Bo Xia Yan, Hong Liu, Yong Bi. Opt. Express, 23 (14), 17727 (2015). DOI: 10.1364/OE.23.017727

[14] T.R. Volk, L.S. Kokhanchik, R.V. Gainutdinov, Y.V. Bodnarchuk, S.D. Lavrov. J. Adv. Dielect., 8(2), 1830001 (2018). DOI: 10.1142/S2010135X18300013

[15] L. Arizmendi. Phys. Stat. Sol. A, 20 (2), 253 (2004). DOI: $10.1002 /$ pssa.200303911

[16] S.C. Abrahams, P. Marsh. Acta. Cryst., B42, 61 (1986). DOI: $10.1107 / \mathrm{S} 0108768186098567$

[17] A.P. Wilkinson, A.K. Cheerham, R.H. Jarman. J. Appl. Phys., 74 (5), 3080 (1993). DOI: 10.1063/1.354572

[18] G. Dominial-Dzik, W. Ryba-Romanowski, M.N. Palatnikov, N.V. Sidorov, V.T. Kalinnikov. J. Mol. Struct., 704 (1), 139 (2004). DOI: 10.1016/j.molstruc.2004.01.063

[19] W. Ryba-Romanowski, I. Sokolska, G. Dominiak-Dzik, S. Golab. J. Alloys and Compounds, 300 (2), 152 (2000). DOI: $10.1016 / \mathrm{S} 0925-8388(99) 00715-\mathrm{X}$

[20] W. Ryba-Romanowski, S. Golab, G. Dominiak-Dzik, M.N. Palatnikov, N.V. Sidorov. Appl. Phys. Lett., 78 (23), 3610 (2001). DOI: $10.1063 / 1.1376660$

[21] R. Lisiecki, B. Macalik, R. Kowalski, J. Komar, W. Ryba-Romanowski. Crystals, 10|,(11), 1034 (2020). DOI: $10.3390 /$ cryst10111034

[22] Li Dai, Shunxiang Yang, Ruirun Chen, Chunrui Liu, Xianbo Han, Yu Shao. J. Luminescence, 217, 116773 (2020). DOI: 10.1016/j.jlumin.2019.116773

[23] М.Н. Палатников, Н.В. Сидоров, И.В. Бирюкова, О.Б. Щербина, В.Т. Калинников. Перспективные материалы, 2, 93 (2011).

[24] Н.В. Сидоров, А.А. Яничев, М.Н. Палатников, А.А. Габаин. Опт. и спектр., 116 (2), 306 (2014).

DOI: $10.7868 / \mathrm{S} 0030403414010206$ [N.V. Sidorov, A.A. Yanichev, M.N. Palatnikov, A.A. Gabain. Opt. Spectr., 116 (2), 281 (2014). DOI: 10.1134/S0030400X14010202]

[25] Н.В. Сидоров, Т.Р. Волк, Б.Н. Маврин, В.Т. Калинников. Ниобат лития: дефекты, фоторефракция, колебательный спектр, поляритоны (Наука, М., 2003).

[26] N. Zotov, H. Boysen, F. Frey, T. Metzger, E. Born. J. Phys. Chem. Solids, 55(2), 145 (1994). DOI: 10.1016/00223697(94)90071-X
[27] Homer Fay, W.J. Alford, H.D. Dess. Appl. Phys. Lett., 12 (3), 89 (1968). DOI: 10.1063/1.1651911

[28] P. Lerner, C. Legras, J.P. Dumas. J. Cryst. Growth, 3 (4), 231 (1968). DOI: 10.1016/0022-0248(68)90139-5

[29] L. Kovacs, K. Polgar. Cryst. Res. Technol., 21 (6), K101 (1986).

[30] N. Iyi, K. Kitamura, F. Izumi, J.K. Yamamoto, T. Hayashi, H. Asano, S. Kimura. J. Sol. Stat. Chem., 101 (2), 340 (1992). DOI: 10.1016/0022-4596(92)90189-3

[31] H.J. Donnerberg, S.M. Tomlinson, C.R.A. Catlow. J. Phys. Chem. Solids, 52 (1), 201 (1991). DOI: 10.1016/00223697(91)90065-8

[32] G.E. Peterson, A. Carnevale. J. Chemical Physics, 56 (10), 4848 (1972). DOI: $10.1063 / 1.1676960$

[33] F.P. Safaryan, R.S. Feigelson, A.M. Petrosyan. J. Appl. Phys., 85 (12), 8079 (1999). DOI: 10.1063/1.370645

[34] R.M. Araujo, K. Lengyel, R.A. Jackson, L. Kovacs, M.E.G. Valerio. J. Phys.: Condens. Matter., 19, 046211 (2007). DOI: $10.1088 / 0953-8984 / 19 / 4 / 046211$

[35] F. Abdi, M.D. Fontana, M. Aillerie, P. Bourson. Appl. Phys. A, 83, 427 (2006). DOI: 10.1007/s00339-006-3565-5

[36] K. Maaider, N. Masaif, A. Khalil. Indian J. Phys., 95, 275 (2021). DOI: 10.1007/s12648-020-01696-5

[37] Yongfa Kong, Jingjun Xu, Xiaojun Chen, Cunzhou Zhang, Wanlin Zhang, Guangyin Zhang. J. Appl. Phys., 87 (9), 4410 (2000). DOI: $10.1063 / 1.373085$

[38] Н.В. Сидоров, Б.Н. Маврин, П.Г. Чуфырев, М.Н. Палатников. Фононные спектры монокристаллов ниобата лития (Издательство Кольского научного центра РАН, Апатиты, 2012).

[39] Н.В. Сидоров, Н.А. Теплякова, А.А. Яничев, М.Н. Палатников, О.В. Макарова, Л.А. Алёшина, А.В. Кадетова. Неорганические материалы, 53 (5), 491 (2017).

DOI: 10.7868/S0002337X17050177 [N.V. Sidorov, N.A. Teplyakova, A.A. Yanichev, M.N. Palatnikov, O.V. Makarova, L.A. Aleshina, A.V. Kadetova. Inorganic materials, 53 (5), 489 (2017). DOI: 10.1134/S002016851705017X].

[40] K. Lengyel, A. Peter, L. Kovacs, G. Corradi, L. Palfavi, J. Hebling, M. Unferdorben, G. Dravecz, I. Hajdara, Zs. Szaller, K. Polgar. Appl. Phys. Rev., 2 (4), 040601 (2015).

[41] F. Abdi, M. Aillerie, M. Fontana, P. Bourson, T. Volk, B. Maximov, S. Sulyanov, N. Rubinina, M. Wohlecke. Appl. Phys. B, 68, 795 (1999). DOI: 10.1007/s003409901469

[42] T. Volk, B. Maximov, T. Chernaya, N. Rubinina, M. Wöhlecke, V. Simonov. Appl. Phys. B, 72 (6), 647 (2001). DOI: $10.1007 / \mathrm{s} 003400100548$

[43] А.В. Кадетова. Влияние легирования на структурные особенности ниобата лития: дис. ... магистра по направлению „Электроника и наноэлектроника“ (ПетрГУ, Петрозаводск, 2018).

[44] J.J. Amodei, D.L. Staebler. Appl. Phys. Lett., 18, 540 (1971). DOI: $10.1063 / 1.1653530$

[45] D. von der Linde, A.M. Glass, K.F. Rodgers. Appl. Phys. Lett., 25 (3), 155 (1974). DOI: 10.1063/1.1655420

[46] Ye Ming, E. Kratzig, R. Orlowski. Phys. Stat. Sol. A, 92 (1), 221 (1985). DOI: 10.1002/pssa.2210920121

[47] L. Tsarukyan, R. Hovsepyan, R. Drampyan. Photonics and Nanostructures - Fundamentals and Applications, 40, 100793 (2020). DOI: 10.1016/j.photonics.2020.100793

[48] J.E. Midwinter, J. Warner. J. Appl. Phys., 38 (2), 519 (1967). DOI: $10.1063 / 1.1709367$ 
[49] A. Hordvik, H. Schlossberg. Appl. Phys. Lett., 20 (5), 197 (1972). DOI: $10.1063 / 1.1654106$

[50] Н.В. Сидоров, М.В. Смирнов, М.Н. Палатников. ЖПС, 87 (2), 194 (2020). [N.V. Sidorov, M.V. Smirnov, M.N. Palatnikov. J. Appl. Spectrosc., 87 (2), 212 (2020). DOI: $10.1007 / \mathrm{s} 10812-020-00986-4]$

[51] A. Harhira, L. Guilbert, P. Bourson, H. Rinnert. Phys. Stat. Sol. C, 4 (3), 926 (2007). DOI: 10.1002/pssc.200673755

[52] A. Krampf, S. Messerschmidt, M. Imlau. Scientific Reports, 10, 11397 (2020). DOI: 10.1038/s41598-020-68376-6

[53] C. Fischer, M. Wöhlecke, T. Volk, N. Rubinina. Phys. Stat. Sol. A, 137 (1), 247 (1993). DOI: 10.1002/pssa.2211370122

[54] F. Klose, M. Wohlecke, S. Kapphan. Ferroelectrics, 92 (1), 181 (1989). DOI: 10.1080/00150198908211324

[55] T.P.J. Han, F. Jaque, V. Bermudez, E. Diefuez. Chem. Phys. Lett., 369 (5-6), 519 (2003). DOI: 10.1016/S00092614(02)02028-6

[56] M.G. Clark, F.J. DiSalvo, A.M. Glass, G.E. Peterson. J. Chem. Phys., 59 (12), 6209 (1973). DOI: 10.1063/1.1680000

[57] M.V. Ciampolillo, M. Bazzan, C. Sada, N. Argiolas, A. Zaltron, E. Cattaruzza, S. Mignoni, P. Bourson, M.D. Fontana, M. Bianconi. Ferroelectrics, 389 (1), 142 (2009). DOI: 10.1080/00150190902993275

[58] L.E. Halliburton, K.L. Sweeney, C.Y. Chen. Nuclear Instruments and Methods in Physics Research B, 1(2-3), 344 (1984). DOI: 10.1016/0168-583X(84)90090-9

[59] D.M. Krol, G. Blasse, R.C. Powell. J. Chem. Phys., 73 (1), 163 (1980). DOI: $10.1063 / 1.439901$

[60] J. Llopis, C. Ballesteros, R. Gonzalez, Y. Chen. J. Appl. Phys., 56 (2), 460 (1984). DOI: 10.1063/1.333932

[61] Н.В. Сидоров, М.В. Смирнов, М.Н. Палатников, В.Б. Пикулев. Опт. и спектр., $129(5), 634$ (2021). DOI: $10.21883 /$ OS.2021.05.50891.248-20

[62] Richard C. Powell, Edwin E. Freed. J. Chem. Phys., 70 (10), 4681 (1979). DOI: 10.1063/1.437253

[63] Е.В. Строганова. Исследование, синтез и выращивание оптических градиентно-активированных кристаллов на основе ниобата лития. Автореф. докт. дис. (ФГБОУ ВО „Кубанский государственный университет“, Краснодар, 2017).

URL: http://docspace.kubsu.ru/docspace/handle/1/1059

[64] В.В. Галуцкий, Е.В. Строганова, Н.А. Яковенко. Опт. и спектр., 110 (3), 436 (2011). [V.V. Galutskii, E.V. Stroganova, N.A. Yakovenko. Opt. Spectrosc. 110 (3), 401 (2011). DOI: $10.1134 / \mathrm{S} 0030400 X 10061049]$

[65] V. Trepakov, A. Skvortsov, S. Kapphan, L. Jastrabik, V. Vorlíček. Ferroelectrics, $239(1), 297$ (2000). DOI: $10.1080 / 00150190008213335$

[66] P. Bourson, M. Aillerie, M. Cochez, M. Ferriol, Y. Zhang, L. Guilbert. Optical Materials, 24(1-2), 111 (2003). DOI: $10.1016 / \mathrm{S} 0925-3467(03) 00113-7$

[67] H.-J. Reyher, R. Schulz, O. Thiemann. Phys. Rev. B, 50 (6), 3609 (1994). DOI: 10.1103/PhysRevB.50.3609

[68] H. Kurz, E. Kratzig, W. Keune, H. Engelmann, U. Gonser, B. Dischler, A. Rauber. Appl. Phys., 12355 (1977). DOI: $10.1007 / \mathrm{BF} 00886038$

[69] O.F. Schirmer, D. von der Linde. Appl. Phys. Lett., 33, 35 (1978). DOI: $10.1063 / 1.90181$

[70] G. Blasse, A. Bril. J. Electrochem. Soc., 115 (10), 1067 (1968). DOI: $10.1149 / 1.2410880$

[71] G. Blasse, L.G.J. De Haart. Materials Chemistry and Physics, 14 (5), 481 (1986). DOI: 10.1016/0254-0584(86)90050-7
[72] O.F. Schirmer. J. Phys.: Condens. Matter, 18, R667 (2006). DOI: $10.1088 / 0953-8984 / 18 / 43 / \mathrm{R} 01$

[73] O.F. Schirmer, O. Thiemann, M. Wohlecke. J. Phys. Chem. Solids, 52 (1), 185 (1991). DOI: 10.1016/00223697(91)90064-7

[74] P. Reichenbach, T. Kämpfe, A. Haußmann, A. Thiessen, T. Woike, R. Steudtner, L. Kocsor, Z. Szaller, L. Kovács, Lukas M. Eng. Crystals, 8 (5), 214 (2018). DOI: $10.3390 /$ cryst 8050214

[75] L. Arizmendi, J.M. Cabrera, F. Agullo-Lopez. J. Phys. C: Solid State Phys., 17, 515 (1984). DOI: 10.1088/00223719/17/3/021

[76] P. Reichenbach, T. Kämpfe, A. Thiessen, M. Schroder, A. Haußmann, T. Woike, L.M. Eng. J. Appl. Phys., 115 (21), 213509 (2014). DOI: $10.1063 / 1.4881496$

[77] L. Arizmendi, J.M. Cabrera, F. Agullo-Lopez. Solid State Commun., $40(5), 583$ (1981). DOI: 10.1016/00381098(81)90579-2

[78] T. Kampfe, A. Haußmann, L.M. Eng. Phys. Rev. B, 93 (17), 174116 (2016). DOI: 10.1103/PhysRevB.93.174116

[79] S. Messerschmidt, A. Krampf, F. Freytag, M. Imlau, L. Vittadello, M. Bazzan, G. Corradi. J. Phys.: Condens. Matter, 31 (6), 065701 (2018). DOI: 10.1088/1361$648 \mathrm{X} / \mathrm{aaf} 4 \mathrm{df}$

[80] M.H.J. Emond, M. Wiegel, G. Blasse, R. Feigelson. Mat. Res. Bull., $28(10), 1025$ (1993). DOI: 10.1016/00255408(93)90140-9

[81] М.В. Смирнов, Н.В. Сидоров, М.Н. Палатников, В.Б. Пикулев. Труды Кольского научного центра, 10 (3), 323 (2019).

[82] В.А. Голенищев-Кутузов, А.В. Голенищев-Кутузов, Р.И. Калимуллин, А.В. Семенников, В.А. Уланов. Известия РАН. Серия физическая, 84 (12), 1754 (2020). DOI: $10.31857 / \mathrm{S} 0367676520120212$

[83] В.Ю. Яковлев, Е.В. Кабанова, Т. Вебер, П. Пауфлер. ФТТ, $43(8), 1520$ (2001)

[84] И.Ш. Ахмадуллин, В.А. Голенищев-Кутузов, С.А. Мигачев. ФTT, 40 (6), 1109 (1998).

[85] J. Koppitz, O.F. Schirmer, A.I. Kuznetsov. Europhys. Lett., 4 (9), 1055 (1987). DOI: 10.1209/0295-5075/4/9/017

[86] J.G. Murillo, G. Herrera, A. Vega-Rios, S. Flores-Gallardo, A. Duarte-Moller, J. Castillo-Torres. Optical materials, 62, 639 (2016). DOI: 10.1016/j.optmat.2016.10.059

[87] В.М. Фридкин. Сегнетоэлектрики - полупроводники (Наука, М., 1976).

[88] Yanl Li, Lili Li, Xiufeng Cheng, Xian Zhao. J. Phys. Chem. C, 121 (16), 8969 (2017). DOI: 10.1021/acs.jpcc.7b01274

[89] Т. Мосс, Г. Баррел, Б. Эллис. Полупроводниковая оптоэлектроника, перевод с английского А.А. Гиппиуса, А.Н. Ковалева, под ред. С.А. Медведева. (Мир, М., 1976). 